\title{
Ocean heat uptake processes: a model intercomparison
}

Article

Published Version

Exarchou, E., Kuhlbrodt, T., Gregory, J. M. and Smith, R. S. (2015) Ocean heat uptake processes: a model intercomparison. Journal of Climate, 28 (2). pp. 887-908. ISSN 1520-0442 doi: https://doi.org/10.1175/JCLI-D-14-00235.1 Available at https://centaur.reading.ac.uk/38328/

It is advisable to refer to the publisher's version if you intend to cite from the work. See Guidance on citing.

To link to this article DOI: http://dx.doi.org/10.1175/JCLI-D-14-00235.1

Publisher: American Meteorological Society

All outputs in CentAUR are protected by Intellectual Property Rights law, including copyright law. Copyright and IPR is retained by the creators or other copyright holders. Terms and conditions for use of this material are defined in the End User Agreement.

\section{www.reading.ac.uk/centaur}

\section{CentAUR}

Central Archive at the University of Reading

Reading's research outputs online 


\title{
Ocean Heat Uptake Processes: A Model Intercomparison
}

\author{
Eleftheria Exarchou, Till Kuhlbrodt, Jonathan M. Gregory, and Robin S. SMith \\ National Centre for Atmospheric Science-Climate, Department of Meteorology, University of Reading, Reading, \\ United Kingdom
}

(Manuscript received 27 March 2014, in final form 10 October 2014)

\begin{abstract}
The quasi-equilibrium heat balances, as well as the responses to $4 \times \mathrm{CO}_{2}$ perturbation, are compared among three global climate models with the aim to identify and explain intermodel differences in ocean heat uptake (OHU) processes. It is found that, in quasi equilibrium, convective and mixed layer processes, as well as eddy-related processes, cause cooling of the subsurface ocean. The cooling is balanced by warming caused by advective and diapycnally diffusive processes. It is also found that in the $\mathrm{CO}_{2}$-perturbed climates the largest contribution to OHU comes from changes in vertical mixing processes and the mean circulation, particularly in the extratropics, caused both by changes in wind forcing and by changes in high-latitude buoyancy forcing. There is a substantial warming in the tropics: a significant part of which occurs because of changes in horizontal advection in extratropics. Diapycnal diffusion makes only a weak contribution to the OHU, mainly in the tropics, because of increased stratification. There are important qualitative differences in the contribution of eddy-induced advection and isopycnal diffusion to the OHU among the models. The former is related to the different values of the coefficients used in the corresponding scheme. The latter is related to the different tapering formulations of the isopycnal diffusion scheme. These differences affect the OHU in the deep ocean, which is substantial in two of the models, with the dominant region of deep warming being the Southern Ocean. However, most of the OHU takes place above $2000 \mathrm{~m}$, and the three models are quantitatively similar in their global OHU efficiency and its breakdown among processes and as a function of latitude.
\end{abstract}

\section{Introduction}

The largest contributor to present sea level rise is ocean thermal expansion (Church et al. 2011, 2013). The uncertainty in the projections of thermal expansion, estimated with global climate model simulations, is relatively large. The projections of thermal expansion by the end of this century, for example, calculated from models used in phase 5 of the Coupled Model Intercomparison Project (CMIP5) is $18 \mathrm{~cm}$ under the representative concentration pathway 4.5 (RCP4.5) scenario, whereas the intermodel $2 \sigma$ range $( \pm 1$ standard deviation) is $6 \mathrm{~cm}$ (Yin 2012). Kuhlbrodt and Gregory (2012), in a study that involved simulations from CMIP5 models forced with increasing $\mathrm{CO}_{2}$ concentration at rate of $1 \% \mathrm{yr}^{-1}$, found that about half of the intermodel spread in thermal expansion is caused by the spread in

Corresponding author address: Eleftheria Exarchou, Institut Català de Ciències del Clima (IC3), Carrer Trueta, 203, 08005 Barcelona, Spain.

E-mail: eleftheria.exarchou@ic3.cat ocean heat uptake (i.e., change in ocean heat content). They also found that about half of the model spread in ocean heat uptake, in turn, is caused by differences in ocean vertical heat transport processes among the different models. In other words, the uncertainty in the efficiency with which heat is transferred from the surface into the deeper ocean significantly contributes to the uncertainty in both ocean heat uptake (OHU) and thermal expansion projections. In addition, this uncertainty also contributes to the uncertainty in transient surface warming projections.

The understanding of the mechanisms that lead to OHU relies on a detailed understanding of the ocean heat balance, not only how the different ocean heat transport processes determine the heat balance in a steady state but also how they contribute to OHU in a $\mathrm{CO}_{2}$-perturbed climate. Despite the potentially significant impact on future sea level rise and transient surface warming projections, there are only a handful of studies that investigate mechanisms leading to OHU. The first modeling study to perform an analysis of the ocean heat balance was Manabe et al. (1990). They 
analyzed the heat balance of the Southern Ocean, where the $\mathrm{OHU}$ is particularly strong, and showed that $\mathrm{OHU}$ is caused by reduction of convective ocean heat loss. Convection in the high latitudes is caused by atmospheric cooling and leads to an exchange between the warmer deeper water masses and the colder surface ones, hence leading to an upward heat flux. Atmospheric $\mathrm{CO}_{2}$ increase leads to a surface warming and/or freshening, reducing convection and thus yielding a reduced convective heat loss. This mechanism has been found in most subsequent modeling studies (e.g., Gregory 2000; Huang et al. 2003).

More recent modeling studies have discussed additional mechanisms affecting OHU. For example, Gregory (2000) found that isopycnal diffusion in the Southern Ocean in a quasi-equilibrium state is associated with upward heat fluxes. Atmospheric $\mathrm{CO}_{2}$ increase leads to Southern Ocean heat uptake through a reduction in isopycnal diffusion and a consequent reduction in the corresponding upward heat fluxes. Such a mechanism has also been seen in a study that uses an idealized eddypermitting ocean model (Morrison et al. 2013). In addition, Gregory (2000) found that the reduced convection and the associated deep-water formation in the high latitudes leads to reduced upwelling of cold water masses in the low latitudes, leading, therefore, to net $\mathrm{OHU}$ in the low latitudes. Huang et al. (2003) explored the impact of eddy advection, parameterized with the Gent and McWilliams (1990, hereafter GM) scheme, on OHU of the deep ocean. They used an ocean model and its adjoint with an idealized setup and showed that eddy advection in quasi equilibrium is associated with upward heat flux in the North Atlantic and Southern Ocean, and, therefore, cools the deeper layers of the ocean. $\mathrm{CO}_{2}$ increase resulted in surface warming and a flattening of the isopycnal surfaces, which led to reduced eddy advection and, therefore, reduced cooling, or enhanced warming, in the deeper layers of the North Atlantic and Southern Ocean. The effect of isopycnal diffusion could not be explored in Huang et al. since their eddy parameterization did not separate isopycnal diffusion from eddy-induced advective transport. In addition, whether the slopes of the isopycnal surfaces and correspondingly the eddy activity increase as a response to $\mathrm{CO}_{2}$ increase is a matter of debate among modeling studies, because of dependencies on ocean resolution and disagreements with observations (e.g., Böning et al. 2008).

Bouttes et al. (2012) studied the impact of wind stress change on ocean temperature and sea level rise. The projected wind stress change caused by $\mathrm{CO}_{2}$ increase in climate models is generally a strengthening and poleward shift of the zonal component over the Southern Ocean (Fyfe and Saenko 2006; Sen Gupta et al. 2009).
Simulations forced only with wind stress changes showed warming (and corresponding sea level rise) in the midlatitude Southern Ocean, which was caused by wind-induced changes in advective heat transport. Near Antarctica, on the other hand, increased convection caused ocean cooling and sea level fall. The study of Frankcombe et al. (2013) examined separately the role of the strengthening and poleward shift of the wind stress with an eddy-permitting ocean model. They found that, while the increase of the wind stress led to OHU and sea level rise, the poleward shift of the winds caused ocean heat loss and sea level fall. An additional mechanism discussed in Exarchou et al. (2013) associates OHU in the deeper Southern Ocean with changes in advection. In the deeper ocean, the circulation poleward of $65^{\circ} \mathrm{S}$ is reduced as a result of reduced convection, leading, therefore, to reduced advective cooling, or enhanced warming, in the Southern Ocean.

Banks and Gregory (2006) investigated the hypothesis that heat is being distributed in the ocean interior like a passive tracer along fixed ventilation pathways for ocean water masses, a view depicted, for example, in Jackett et al. (2000) and Russell (2006). The main finding was that heat cannot be seen as a passive tracer being transported from the surface into the ocean interior, but instead it is affected by circulation changes and has a strong diapycnal component.

The mechanisms in the modeling studies described above are not universally valid across all models. Instead, large intermodel differences suggest that OHU mechanisms are probably model dependent. The goal of the current study is to identify and explain underlying causes that create differences in ocean heat transport processes among different models. For this purpose, we use global warming experiments from three different global climate models that are either part of or based on models that are part of the CMIP5 framework. These models have available heat processes diagnostics for the ocean temperature equations on each model grid point, which enables a detailed analysis of how the heat balance is maintained in quasi equilibrium but also of how this balance is modified because of $\mathrm{CO}_{2}$ perturbation. The availability of such diagnostics further enables a description of the geographical characteristics of the heat uptake and an assessment of the relative importance of the different latitude bands to the total ocean heat uptake. Furthermore, using offline calculations, we are able to reconstruct the heat processes diagnostics. Such reconstructions allow us to fill possible gaps in the online diagnostics; they also enable us, by modifying details of the numerical implementations, to examine possible sensitivities to such details. Overall, an improved understanding of the differences in the 
mechanisms that lead to OHU can contribute to the ongoing effort in understanding and eventually constraining the uncertainty in future sea level rise and surface warming projections.

\section{Decomposing the temperature equation}

Heat enters the upper layers of the ocean through surface fluxes and penetrating solar radiation. It is then transported into the deeper layers by several processes. Both heat uptake and heat transport processes are represented by the temperature equation. To evaluate such processes, we directly decompose diagnostically the temperature equation of a model into its separate components: that is, to separately diagnose online the rate of temperature change caused by each of the different processes. The equation of temperature in an ocean model can be represented as

$$
\begin{aligned}
\rho_{0} c_{p} \frac{\partial \theta}{\partial t}= & \nabla \cdot\left(F_{\mathrm{ADV}}+F_{\mathrm{VM}}+F_{\mathrm{ISO}}+F_{\mathrm{DIA}}\right. \\
& \left.+F_{\mathrm{EIA}}+F_{\mathrm{SF}}\right),
\end{aligned}
$$

where $\theta$ is potential temperature (we will refer to it simply as temperature). We use potential temperature because models generally apply heat conservation in this quantity, even if this approach is thermodynamically not accurate, and could lead to energy production/ destruction terms in the energy balance (e.g., McDougall 2003; Tailleux 2010). Equation (1) represents how the convergence of heat flux $\rho_{0} c_{p} \partial \theta / \partial t$ (in $\mathrm{W} \mathrm{m}^{-3}$, where $\rho_{0}=1023 \mathrm{~kg} \mathrm{~m}^{-3}$ is a reference density and $c_{p}=$ $3992 \mathrm{~J} \mathrm{~kg}^{-1} \mathrm{~K}^{-1}$ is heat capacity) is determined by the convergences of fluxes caused by a combination of different heat uptake and heat transport processes. These processes are the resolved advection, vertical mixing (defined here as the sum of convection and mixed layer physics), isopycnal diffusion (mainly horizontal except in high latitudes, not including eddy advection), diapycnal diffusion (mainly vertical except in high latitudes), eddy-induced advection, and fluxes associated with processes that are important mainly near the sea surface or within the upper $120 \mathrm{~m}$ (i.e., surface fluxes, including penetrating solar radiation, sea surface fluxes, and fluxes associated with sea ice physics). For reference, the acronyms for the processes are listed in Table 1. The precise form of the individual terms in Eq. (1) depends on the model formulation. We are using here the term "convergence" (units of $\mathrm{W} \mathrm{m}^{-3}$ ) regardless of whether it actually denotes convergence or divergence of heat flux. Positive convergences imply warming, and negative convergences imply cooling. In addition, the reason that we use the partial rather than the total time
TABLE 1. List of acronyms for the processes.

\begin{tabular}{ll}
\hline SF & Surface fluxes \\
ADV & Advection \\
CON & Convection \\
ML & Mixed layer \\
VM & Vertical mixing \\
ISO & Isopycnal diffusion \\
DIA & Diapycnal diffusion \\
EIA & Eddy-induced advection \\
EHF & Eddy heat fluxes \\
\hline
\end{tabular}

derivative of $\theta$ in Eq. (1) is that it separates out the contribution of the advective heat transport to the total heat balance.

To understand and analyze the relative contribution of each heat uptake and transport process of Eq. (1) to the total heat balance in both control and $\mathrm{CO}_{2}$ perturbed climate, we diagnose online at each time step the rates of temperature change $\partial \theta / \partial t$ caused by each of these processes and convert them to heat flux convergences by multiplying them with the volumetric heat capacity $\rho_{0} c_{p}$. These temperature tendency diagnostics are averaged over the model's diagnostic time interval (usually monthly) and saved on the model threedimensional grid. The sum of these diagnostics represents the total heat flux convergence. In quasi equilibrium, the global mean of the total convergence is a near-zero term but not exactly zero because of the climate drift, which is a common feature among global coupled climate models because of the spinup runs being much shorter than the typically very long time scales the deep ocean needs to reach equilibrium (e.g., England 1995; Sen Gupta et al. 2013). In the $\mathrm{CO}_{2}$-perturbed climate, the global mean of the total convergence is a positive term and indicates the net global-mean ocean warming. Analyzing the temperature tendency diagnostics allows us thus to directly assess the role of heat transport processes in both the control and $\mathrm{CO}_{2}$ perturbed climates but also enables a description of their geographical distribution.

In the present study, we wish to focus on the impact of the ocean on forced transient climate change on time scales that are longer than the time scales that characterize the internally generated variability of the surface climate. The ocean can be approximately described by two distinct layers that are associated with different time scales: one upper layer with small heat capacity, whose temperature change varies together with surface temperature change, and a deeper layer with large heat capacity, which mostly determines thermal expansion (Gregory 2000; Held et al. 2010; Bouttes et al. 2013; Geoffroy et al. 2013). Correlations of annual-mean temperatures between surface and subsurface layers 
TABLE 2. Heat transport processes that appear in the equation of temperature tendency Eq. (1), numerical schemes for parameterizations of subgrid-scale processes, and availability of online diagnostics of these processes. "Yes" denotes that online diagnostics are available; otherwise, the method to infer it offline is mentioned.

\begin{tabular}{|c|c|c|c|}
\hline & HadCM3 & HiGEM1.2 & MPI-ESM \\
\hline Advection & Resolved (without eddies) & $\begin{array}{l}\text { Residual advection resolved (with } \\
\text { eddies) }\end{array}$ & Resolved (without eddies) \\
\hline Online diagnostic & Yes & Inferred from $\overline{\nabla \cdot(\overline{\mathbf{u}} \bar{\theta})}$ & Yes \\
\hline Convection & Convective adjustment & Convective adjustment & Enhanced DIA \\
\hline Online diagnostic & Yes & Yes & $\begin{array}{l}\text { Yes for CON + ML + DIA; } \\
\text { POTTE to separate terms }\end{array}$ \\
\hline Mixed layer & Kraus and Turner (1967) & Kraus and Turner (1967) & $\begin{array}{l}\text { Enhanced wind mixing term in } \\
\text { DIA inside the mixed layer }\end{array}$ \\
\hline Online diagnostic & Yes & Yes & $\begin{array}{l}\text { Yes for CON + ML + DIA; } \\
\text { POTTE to separate terms }\end{array}$ \\
\hline Isopycnal diffusion & $\begin{array}{l}\text { Griffies et al. (1998) and } \\
\text { DM tapering scheme; } \\
\kappa_{\text {iso }}=1000 \mathrm{~m}^{2} \mathrm{~s}^{-1}\end{array}$ & $\begin{array}{l}\text { Griffies et al. (1998) and DM } \\
\quad \text { tapering scheme; } \kappa_{\text {iso }}=500 \mathrm{~m}^{2} \mathrm{~s}^{-1}\end{array}$ & $\begin{array}{l}\text { Griffies et al. (1998) and GKW } \\
\text { tapering scheme; } \kappa_{\text {iso }}= \\
32-450 \mathrm{~m}^{2} \mathrm{~s}^{-1}\end{array}$ \\
\hline Online diagnostic & No; POTTE & No; POTTE & Yes \\
\hline Diapycnal diffusion & $\begin{array}{l}\text { PP scheme; } \kappa_{\mathrm{bg}}=10^{-5} \mathrm{~m}^{2} \mathrm{~s}^{-1} \\
\text { linear increase with depth }\end{array}$ & $\begin{array}{l}\text { PP scheme; } \kappa_{\mathrm{bg}}=10^{-5} \mathrm{~m}^{2} \mathrm{~s}^{-1} \\
\text { linear increase with depth }\end{array}$ & PP scheme; $\kappa_{\mathrm{bg}}=10^{-5} \mathrm{~m}^{2} \mathrm{~s}^{-1}$ \\
\hline Online diagnostic & $\begin{array}{l}\text { Yes for ISO + DIA; POTTE } \\
\text { to separate terms }\end{array}$ & $\begin{array}{l}\text { Yes for ISO + DIA; POTTE to } \\
\text { separate terms }\end{array}$ & $\begin{array}{l}\text { Yes for CON + ML + DIA; } \\
\text { POTTE to separate terms }\end{array}$ \\
\hline Eddy-induced advection & $\begin{array}{l}\text { GWMM95; Wright (1997); } \\
\kappa_{\mathrm{GM}}=300-2000 \mathrm{~m}^{2} \mathrm{~s}^{-1}\end{array}$ & "Permitted" & GWMM95; $\kappa_{\mathrm{GM}}=9-116 \mathrm{~m}^{2} \mathrm{~s}^{-1}$ \\
\hline Online diagnostic & Yes & $\begin{array}{l}\text { Inferred from } \overline{\nabla \cdot(\mathbf{u} \theta)}-\overline{\nabla \cdot(\overline{\mathbf{u}} \bar{\theta})} \text {; } \\
\text { not strictly equivalent to EIA, } \\
\text { referred to as EHF }\end{array}$ & Yes \\
\hline
\end{tabular}

decline below $100 \mathrm{~m}$ or so in all three models. We therefore exclude from our analysis the top $120 \mathrm{~m}$ (the precise layer depth is subject to the vertical discretization of each model) and the ocean heat uptake/transport processes that are at work mostly at the top layers $\left[F_{\mathrm{SF}}\right.$ term in Eq. (1)]. This means that we do not discuss the role of surface fluxes and penetrating solar radiation, which are the terms that dominate in the global volumemean ocean heat balance. The layers we exclude hold about $17 \%-25 \%$ of the total ocean heat uptake (at the particular time period we use, the fraction decreases as time passes).

\section{Models}

We use in our study three different global climate models, Hadley Centre Coupled Model, version 3 (HadCM3); High-Resolution Global Environmental Model, version 1.2 (HiGEM1.2); and Max Planck Institute (MPI) Earth System Model (MPI-ESM). Here we describe briefly these models and discuss their main differences in the choices of parameterizations of subgrid-scale processes appearing in the equation of ocean temperature [Eq. (1)]. The differences in the choices of numerical schemes among the models are summarized in Table 2. Table 2 also summarizes which online diagnostics are available for each model, and appendix A gives a detailed description of offline reconstructions of diagnostics that are not available online, using software called the Partial Ocean Temperature Tendency Emulator (POTTE).

\section{a. HadCM3}

HadCM3 (Gordon et al. 2000) is one of the models used in CMIP5. It includes an atmospheric model, with horizontal resolution $2.5^{\circ} \times 3.75^{\circ}$ and 19 vertical levels, and an ocean model, which is a rigid lid, depth-level, primitive equation general circulation model, with horizontal resolution equal to $1.25^{\circ} \times 1.25^{\circ}$ and 20 vertical levels. Isopycnal diffusivity follows the isopycnal scheme of Griffies et al. (1998), with a diffusion coefficient equal to $1000 \mathrm{~m}^{2} \mathrm{~s}^{-1}$. The eddy-induced tracer transport is parameterized following Gent et al. (1995, hereafter GWMM95), with a time-dependent eddy-induced diffusion coefficient that is calculated as a function of the stratification and has values from 300 to $2000 \mathrm{~m}^{2} \mathrm{~s}^{-1}$. The vertical mixing of tracers is based on the Richardson number-dependent formulation by Pacanowski and Philander (1981, hereafter PP), with a background diffusivity equal to $\kappa_{\mathrm{bg}}=10^{-5} \mathrm{~m}^{2} \mathrm{~s}^{-1}$ that increases with depth $z$ according to $\kappa_{\mathrm{bg}}=1 \times 10^{-5}+2.8 \times$ $10^{-8} \mathrm{z} \mathrm{m}^{2} \mathrm{~s}^{-1}$. Mixed layer physics are parameterized using the Kraus-Turner mixed layer scheme (Kraus and Turner 1967). Convection is parameterized using the convective adjustment scheme of Rahmstorf (1993). 


\section{b. HiGEM1.2}

HiGEM1.2 is based on the first version of the Met Office Hadley Centre Global Environmental Model (HadGEM1), which is part of the dataset from phase 3 of CMIP (CMIP3). The ocean of HiGEM1.2 is similar to the ocean of the second version (HadGEM2), which is part of the CMIP5 dataset. In HiGEM1.2, the horizontal resolution is $0.83^{\circ}$ latitude $\times 1.25^{\circ}$ longitude for the atmosphere and $1 / 3^{\circ} \times 1 / 3^{\circ}$ for the ocean (Shaffrey et al. 2009). The ocean model has 40 vertical levels. The high resolution of the ocean model component in HiGEM1.2 allows for mesoscale eddies to be partly resolved, particularly in low latitudes. It also allows for better representation of steep gradients such as in western boundary currents (Shaffrey et al. 2009). Isopycnal diffusivity follows the Griffies et al. (1998) scheme, with a diffusion coefficient equal to $500 \mathrm{~m}^{2} \mathrm{~s}^{-1}$. There is no scheme used for eddy-induced tracer transport. The vertical mixing of tracers follows the PP scheme in a similar way as in HadCM3 but with different Richardson number dependency. Mixed-layer physics and convection are treated as in HadCM3.

\section{c. $M P I-E S M$}

The MPI-ESM is the latest version of the global Earth system model that is developed at the Max Planck Institute for Meteorology. It consists of the new version of the atmosphere spectral model ECHAM6 (Stevens et al. 2013) and the MPI Ocean Model (MPI-OM; Marsland et al. 2003). In our study we use the low-resolution version (MPI-ESM-LR), referring to it simply as MPI-ESM. ECHAM6 is run at spectral T63 horizontal resolution $\left(\approx 1.876^{\circ}\right)$ with 47 vertical levels. MPI-OM is a free-surface, $z$-level, primitive equation ocean general circulation model on a curvilinear grid with horizontal resolution ranging from $15 \mathrm{~km}$ at the poles to $185 \mathrm{~km}$ over the tropical Pacific (approximately $0.13^{\circ}-1.65^{\circ}$ ). It has 40 vertical levels. Isopycnal diffusivity is parameterized following the isopycnal scheme of Griffies et al. (1998), with a grid-size-dependent diffusion coefficient ranging between 32 and $450 \mathrm{~m}^{2} \mathrm{~s}^{-1}$. In addition, eddy-induced tracer transport is parameterized following the GWMM95 formulation, with an eddyinduced diffusion coefficient that is grid-size dependent and has values $9-116 \mathrm{~m}^{2} \mathrm{~s}^{-1}$. The vertical mixing of tracers follows the PP scheme, with a background diffusivity equal to $\kappa_{\mathrm{bg}}=10^{-5} \mathrm{~m}^{2} \mathrm{~s}^{-1}$ that is constant with depth. In addition, turbulent mixing in the ocean mixed layer is assumed to be proportional to the cube of the $10-\mathrm{m}$ wind speed, decaying exponentially with depth and potential density difference to the surface (Marsland et al. 2003). Finally, convection is parameterized as greatly enhanced vertical diffusion in the presence of static instability.

\section{Experiments}

The control simulations are $140 \mathrm{yr}$ long for HadCM3 and MPI-ESM and $70 \mathrm{yr}$ long for HiGEM1.2. HadCM3 and MPI-ESM are initialized from spinup runs that are more than $1000 \mathrm{yr}$ long. Their concentration in greenhouse gases is considered to represent the preindustrial conditions in middle to late nineteenth century. HiGEM1.2, on the other hand, has a shorter spinup run (110 yr long) because of its computational constraints and has a present-day control simulation with greenhouse concentration equal to $345 \mathrm{ppm}$. The control experiments have constant forcing in time, where the aerosol forcing results from natural tropospheric aerosols, and there is no volcanic aerosol forcing. Here, we consider the time means of years 1-70 of the control experiments, and we refer to them as $1 \times \mathrm{CO}_{2-}$ $\mathrm{HadCM} 3,1 \times \mathrm{CO}_{2}-\mathrm{HiGEM}$, and $1 \times \mathrm{CO}_{2}-\mathrm{MPI}-\mathrm{ESM}$ for the three corresponding models.

To analyze the impact of $\mathrm{CO}_{2}$ increase, we analyze 70 -yr-long simulations that are forced 4 times the control $\mathrm{CO}_{2}$ concentration, which is imposed instantaneously at the start of the experiments and remains constant in time for the rest of the simulation. All other forcing is the same as in the control experiments. We refer to the time means of years $1-70$ of these perturbed experiments as "abrupt $4 \times \mathrm{CO}_{2}$." The abrupt $4 \times \mathrm{CO}_{2}$ of HiGEM1.2 is forced with higher $\mathrm{CO}_{2}$ concentration than the other two models, since its control $\mathrm{CO}_{2}$ concentration is also higher. The change in radiative forcing, however, should not be different in HiGEM1.2, because of the logarithmic dependence (Myhre et al. 1998) of the change in radiative forcing $\Delta F$ to $\mathrm{CO}_{2}$ concentration $C\left[\Delta F \sim \ln \left(C / C_{0}\right)\right.$, where $C_{0}$ is the initial $\mathrm{CO}_{2}$ concentration].

In the remainder of the paper, we investigate the changes (or responses) between the time means of years 1-70 of the abrupt $4 \times \mathrm{CO}_{2}$ and the control simulations. We refer to these responses as RES-HadCM3, RESHiGEM, and RES-MPI-ESM for the three corresponding models.

\section{Heat convergences in $1 \times \mathrm{CO}_{2}$}

Here, we discuss the global-mean heat convergences for the heat transport processes below 120-m depth [all terms except $F_{\mathrm{SF}}$ in Eq. (1)]. In the global horizontal means, horizontal components are zero because their global horizontal integrals vanish because of the boundary conditions. The convergences thus give information about vertical processes only.

Figure 1 shows the global-mean heat convergences in $1 \times \mathrm{CO}_{2}$ climate for the three models (time means of all 

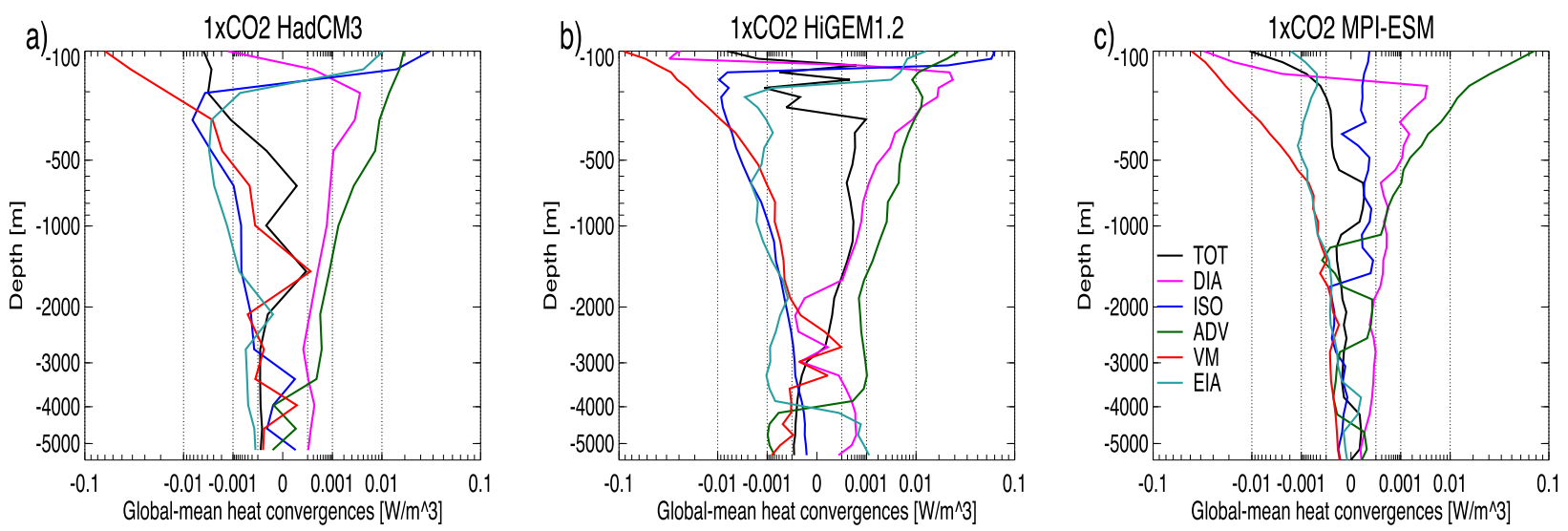

FIG. 1. Global-mean heat convergences $\left(\mathrm{W} \mathrm{m}^{-3}\right.$ ) for (a) $1 \times \mathrm{CO}_{2}-\mathrm{HadCM} 3$, (b) $1 \times \mathrm{CO}_{2}-\mathrm{HiGEM}$, and (c) $1 \times \mathrm{CO}_{2}-\mathrm{MPI}-\mathrm{ESM}$ (where years 1-70 in the control runs have been used here). The axes are scaled by a power law. Dotted lines indicate orders of magnitude.

the years in their control experiments), as well as the sum of these convergences (TOT; black curve), which represents the climate drift. The climate drift is quite small for HadCM3 and MPI-ESM, but larger in HiGEM1.2 for depths of $300-1700 \mathrm{~m}$, reflecting the shorter length of the spinup run of the computationally expensive HiGEM1.2. The total term close to the surface is larger than in the deeper layers, because we have excluded in these plots processes that are strong close to the surface, particularly the penetrating solar radiation.

As a first-order description, the most dominant feature that all three models share is that the heat balance in the global ocean is maintained between cooling VM and warming ADV above $300 \mathrm{~m}$ and between cooling eddy-related processes (ISO and EIA/EHF) and warming ADV and DIA below $500 \mathrm{~m}$ (Fig. 1; abbreviations explained in Table 1). ADV warms the whole water column in $\mathrm{HadCM} 3$, down to $4000 \mathrm{~m}$ in HiGEM1.2 and down to $3000 \mathrm{~m}$ in MPI-ESM (except for depths of 1200-1600 m). In MPI-ESM, the balance below $3000 \mathrm{~m}$ suggests convective cooling, as well as advective cooling (upwelling) of cold Antarctic Bottom Water (AABW) balanced by diapycnal diffusive warming. As a precautionary note here, in the advective term in HiGEM1.2, which is calculated using POTTE, there is a bias below $4000 \mathrm{~m}$, which is related to the differences between the numerical advection schemes used in POTTE and HiGEM1.2 (appendix A). Therefore, we refrain from interpreting the cooling in the HiGEM1.2 advective term below $4000 \mathrm{~m}$. This bias is present in both $1 \times \mathrm{CO}_{2}$ and $4 \times \mathrm{CO}_{2}$ climates; therefore, it cancels out in the responses of the advective convergences of HiGEM1.2 discussed further below.

Vertical mixing is associated with upward heat fluxes that cool the ocean below $120 \mathrm{~m}$ but warm the surface layers. The latitudinal distribution of the zonally and depth-integrated heat flux convergences (Fig. 2) further reveals that vertical mixing occurs in middle and high latitudes in both hemispheres. In the Southern Ocean, the magnitude slightly exceeds the magnitude in the northern latitudes. Strong vertical mixing, associated with the deep-water formation, mostly occurs at high latitudes. The presence of vertical mixing convergences at midlatitudes (at about $35^{\circ}-55^{\circ} \mathrm{N} / \mathrm{S}$ ) with stronger magnitude than in the high latitudes is thus a result of the wind-driven vertical mixing at these latitudes. It seems surprising that the midlatitude vertical mixing convergences are stronger than the high-latitude ones. This does not necessarily imply stronger mixing at midlatitudes; it can be due to warmer waters being mixed up to the upper ocean. Weaker vertical mixing convergences between 700 and $1500 \mathrm{~m}$ in HadCM3 are related to its density stratification being much stronger compared to the other two models.

Eddies, parameterized or resolved, occur where there is baroclinic instability, mostly along steepening isopycnals at high latitudes, particularly in the Southern Ocean (Fig. 2). The heat fluxes caused by eddies are mostly upward causing cooling convergences (solid light-blue lines in Fig. 2), similarly to other models that either resolve or parameterize eddies (Wolfe et al. 2008; Hieronymus and Nycander 2013). The small magnitude of the EIA term in MPI-ESM is related to the small values of the thickness diffusion coefficient (Table 2). The cooling eddy-induced advective convergences generally oppose the warming advective convergences (Figs. 1 and 2). The (parameterized) EIA term in HadCM3 is remarkably similar to the "permitted" EHF term in HiGEM1.2, indicating a satisfactory performance of the GM scheme.

Even if the two coarse models do not generally resolve eddies, some mesoscale activity can be resolved in equatorial regions, where the Rossby radius is significantly 
HadCM3, 138 m - bottom
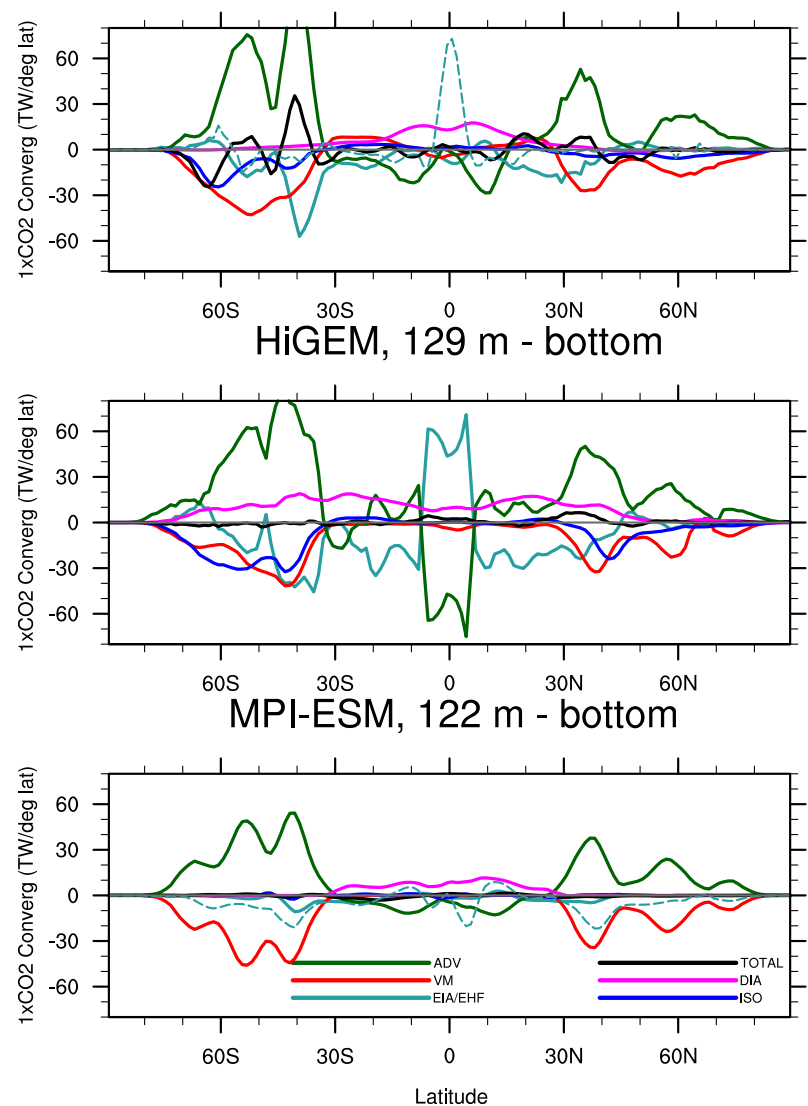

FIG. 2. Zonally and depth integrated heat flux convergences $\left(10^{12} \mathrm{~W}^{\circ}\right.$ lat $^{-1}$; time means for years $\left.1-70\right)$ for $120 \mathrm{~m}$-bottom (subject to models' discretization) for (top) $1 \times \mathrm{CO}_{2}-\mathrm{HadCM} 3$, (middle) $1 \times \mathrm{CO}_{2}-\mathrm{HiGEM}$, and (bottom) $1 \times \mathrm{CO}_{2}-\mathrm{MPI}$-ESM. The light-blue line (EIA in legend) in HiGEM1.2 denotes the EHF. The dashed light-blue line in HadCM3 and MPI-ESM de-

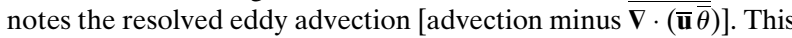
term is already included in the ADV term (green line), but it is shown as an additional term for illustrative purposes. MPI-ESM and HiGEM1.2 data are interpolated onto HadCM3 grid. A 5-point running mean has been applied in the convergences of all three models, except for the advective, eddy advective, and total terms of HiGEM1.2 [green, light-blue, and black lines in (middle), respectively], where a 10-point running mean has been applied instead. The terms ADV and EIA/EHF also include components along the $y$ direction, whereas all the other terms contain only $z$-direction components.

larger than in the middle and high latitudes. We calculated this resolved eddy advection in the two coarse models (dashed light-blue line in top and bottom panels of Fig. 2), as the difference between ADV and $\overline{\nabla \cdot(\overline{\mathbf{u}} \bar{\theta})}$. This term is already part of the ADV term in Fig. 1, and it is shown as a separate term in Fig. 2 in order to illustrate the impact of the resolved eddy advection in the two coarse models. The resolved eddy advection in HadCM3 is particularly large at the equator, much like the EHF term in HiGEM1.2, because of mesoscale activity by tropical instability waves. In MPI-ESM such mesoscale activity is not resolved, because of its large equatorial grid (which reaches $185 \mathrm{~km}$ in the tropical Pacific).

Strong warming advective convergences occur mostly at high latitudes, especially in the Southern Ocean (Fig. 2). A large part of the advective convergences in Fig. 2 are likely associated with horizontal, rather than vertical, fluxes; these cannot be separated in ADV and EIA/EHF. Horizontal advection, however, would be characterized by cooling next to warming regions, which is not generally seen in Fig. 2. The positive vertical ADV convergences in Fig. 1 are related to the wind-driven circulation. The subtropical easterlies and midlatitude westerlies at both hemispheres cause poleward and equatorward Ekman transports, which result in mass and heat convergence and Ekman downwelling of warm surface waters in midlatitude locations, contributing to the ADV convergences of all three models between $30^{\circ}$ and $45^{\circ} \mathrm{N} / \mathrm{S}$ (Fig. 2). Further downwelling of the warm waters into the deeper ocean would cause the deep advective warming seen in Fig. 1. Part of the warming caused by ADV at higher latitudes (poleward of $45^{\circ} \mathrm{N} / \mathrm{S}$ ) is likely caused by horizontal fluxes, which cause cooling between $30^{\circ} \mathrm{S}$ and $30^{\circ} \mathrm{N}$.

DIA is associated with positive warming convergences, implying downward heat fluxes (there is no heat source in the ocean bottom since geothermal heat sources are not considered here), which occur mostly in the tropical latitudes, where solar forcing is strong and the ocean is very stratified (Fig. 2). ISO, on the other hand, is associated with negative convergences mostly at high latitudes in HadCM3 and HiGEM1.2, by the mechanism described in Gregory (2000). Isopycnal surfaces in midlatitude regions are at an angle with isothermal surfaces in a way that there is a temperature gradient on isopycnal surfaces, so that isopycnals are warmer at larger depths. This leads to upward heat fluxes along the isopycnal surfaces, which cools the deeper levels of the ocean and warms the surface levels. In MPI-ESM this mechanism is very weak or even absent because of small isopycnal diffusion coefficients employed (Table 2). An additional reason for the weak isopycnal convergences in MPI-ESM is related to the numerical formulation of the isopycnal scheme. Isopycnal schemes, in order to preserve numerical stability, employ tapering methods, which reduce the isopycnal diffusion coefficient $A_{I}$ over steep slopes, by scaling it with some scaling factor. The tapering formulation in MPI-ESM is different than the one used in HadCM3 and HiGEM1.2. The different tapering formulation in MPIESM results in drastic reduction of the value of the 

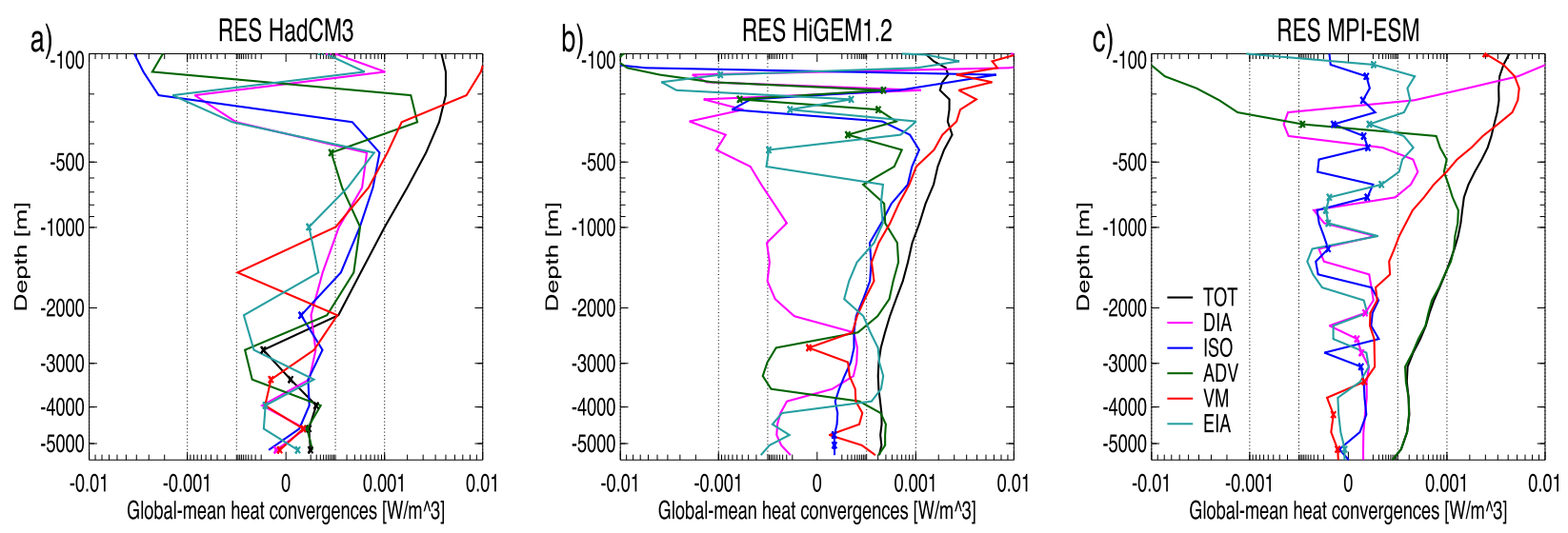

FIG. 3. Responses (i.e., anomalies with respect to the control simulations in Fig. 1) in global-mean heat convergences $\left(\mathrm{W} \mathrm{m}^{-3}\right.$; time means of years 1-70) for (a) RES-HadCM3, (b) RES-HiGEM, and (c) RES-MPI-ESM. The axes are scaled by a power law. Dotted lines indicate orders of magnitude. Starred points denote statistically insignificant responses, defined as the responses where their absolute value is smaller than the $\pm 2 \sigma$ range ( $\sigma$ is temporal standard deviation of heat convergences, calculated from the 70 -yr means of the convergences in the total length of the control simulations).

isopycnal diffusion coefficient in large part of the ocean. The tapering formulation in HadCM3 and HiGEM1.2, on the other hand, affects a much smaller portion of the ocean. We discuss the details of the tapering schemes and their implications on the heat convergences in appendix B.

Overall, an important implication from our results is that none of the models considered here shows the vertical diffusion-advection heat balance (in the global domain) used in advection-diffusion models (e.g., Wigley and Raper 1992; Raper et al. 2001). Such a balance has been hypothesized to hold in the subtropics $\left(30^{\circ} \mathrm{S}-30^{\circ} \mathrm{N}\right)$ by Munk (1966) and Munk and Wunsch (1998). All three models reproduce this balance in the subtropics (Fig. 2), but the global heat balance is dominated by the extratropics. Cooling fluxes from eddies and from vertical mixing, as well as warming fluxes from the mean overturning circulation, determine the balance in the global domain through their strong influence in the high latitudes, particularly in the Southern Ocean. Such a balance is supported, for example, by theoretical arguments (e.g., Hallberg and Gnanadesikan 2006; Nikurashin and Vallis 2012) and demonstrated in other models that either parameterize or resolve eddies (Wolfe et al. 2008; Hieronymus and Nycander 2013).

\section{Changes in heat convergences in response to $\mathrm{CO}_{2}$ increase}

\section{a. Global mean}

Figure 3 shows the differences between the $4 \times \mathrm{CO}_{2}$ and $1 \times \mathrm{CO}_{2}$ global-mean heat flux convergences for the three models. Here, the sum of the responses represents the ocean heat uptake, which is particularly strong in the upper ocean and becomes weaker with depth. Assuming that the climate drift is the same in the $4 \times \mathrm{CO}_{2}$ and $1 \times$ $\mathrm{CO}_{2}$ climates of each model, the drift does not appear in the responses of the heat flux convergences. In addition, we consider the responses to be statistically significant when they are larger than twice the temporal standard deviation of the 70-yr means of heat flux convergences in the total length of the control simulations (starred points in Fig. 3 are statistically insignificant points).

The sum of the responses, or equivalently, the OHU, has different magnitude among the three models, but also different vertical distribution. For example, OHU below $2000 \mathrm{~m}$ is much stronger in HiGEM1.2 and MPI-ESM compared to HadCM3. In fact, less than $4 \%$ of the $120 \mathrm{~m}-$ bottom OHU is stored below $2000 \mathrm{~m}$ in HadCM3, as opposed to about $14 \%-19 \%$ of their respective OHU in MPI-ESM and HiGEM1.2. Integrated from top to bottom (excluding the top $120 \mathrm{~m}$ ) MPI-ESM has the strongest warming, followed by HadCM3, whereas HiGEM1.2 has the weakest warming of all three models.

The predominant processes that lead to OHU are VM and ADV. The responses of these two processes account for more than $80 \%$ of the total OHU occurring below $120 \mathrm{~m}$. Reduction in VM, occurring in the upper ocean, is a result of increasing surface heat or freshwater fluxes in high latitudes, which stabilize the water column, as first discussed in Manabe et al. (1990). Reduced cooling by $\mathrm{VM}$ has a significant contribution to OHU down to about 2000-m depth in HiGEM1.2 and MPI-ESM. In HadCM3, VM contributes to OHU at shallower depths compared to the other two models, owing to its stronger density stratification (not shown).

Response in ADV is the dominant process that leads to OHU at depths where VM changes are small or zero. 
Changes in ADV are significant above $3500 \mathrm{~m}$ in HadCM3, almost everywhere below $500 \mathrm{~m}$ in HiGEM1.2 and below $350 \mathrm{~m}$ in MPI-ESM. The causes of advective heat flux convergences are discussed in the coming paragraphs but also in section 7 .

The remaining $20 \%$ or less of the OHU is due to responses of the other three processes, namely DIA, ISO, and EIA/EHF. Responses of DIA are strong and positive (warming the ocean) mostly closer to the surface, where stratification is strong. In deeper layers, the response in DIA differs among the models. In HadCM3, it has a warming effect almost everywhere. In HiGEM1.2, it cools the ocean between 200 and $2000 \mathrm{~m}$. In MPIESM, it changes sign between 300 and $500 \mathrm{~m}$ and has weak amplitude below $500 \mathrm{~m}$.

The responses in EIA/EHF are significant only in HadCM3 and HiGEM1.2 (even if they have a very weak net effect in HadCM3), whereas they have no effect in MPI-ESM because of low thickness diffusion coefficients (Table 2). In HadCM3, EIA responses warm the ocean between 120 and $2000 \mathrm{~m}$, except for a thin layer close to the surface between 200 and $400 \mathrm{~m}$. Below $2000 \mathrm{~m}$, EIA mostly cools the ocean and has decreased amplitude. The responses in EHF in HiGEM1.2 oppose the changes in ADV below $2500 \mathrm{~m}$ and have mostly a warming impact between 600 and $4000 \mathrm{~m}$. In both models, warming due to EIA/EHF implies decreased EIA/EHF cooling. In HadCM3, the warming is likely related to a flattening of the isopycnals in the high latitudes. In HiGEM1.2, the warming is not straightforward to interpret, because it contains contributions from resolved isopycnal diffusion. It could be either related to a flattening of the isopycnals in the high latitudes or by changes in the isopycnal temperature gradients.

Responses in ISO are significant above $2000 \mathrm{~m}$ in HadCM3 and above $4000 \mathrm{~m}$ in HiGEM1.2 and lead to ocean warming below $300 \mathrm{~m}$. As discussed above, isopycnal diffusion cools the deep ocean because of temperature gradients in isopycnal surfaces at high latitudes. The increase in $\mathrm{CO}_{2}$ leads to a subsurface warming that reduces the temperature gradient in isopycnal surfaces, hence leading to a reduction in the corresponding upward heat fluxes. The weak ISO response in MPI-ESM is related to the very weak ISO convergences in this model, because of the different tapering scheme that is used in its isopycnal diffusion scheme (discussed in detail in appendix B).

\section{b. Spatial and zonal distribution}

The spatial patterns of the depth-integrated OHU (120 m-bottom), as well as the zonal distribution of OHU, are shown in Fig. 4. All three models have two distinct $\mathrm{OHU}$ maxima at about $40^{\circ} \mathrm{N}$ and $40^{\circ}-50^{\circ} \mathrm{S}$. The southern OHU maximum is stronger than the northern one, especially in MPI-ESM. The geographical pattern of the $\mathrm{OHU}$ is in roughly good agreement with the OHU pattern in CMIP3 models (Kuhlbrodt and Gregory 2012). Here we have to take into account that we use different greenhouse forcing and different time periods compared to the CMIP3 models, where the Special Report on Emissions Scenarios (SRES) A1B emissions scenario was used and the model integrations were $100 \mathrm{yr}$ long, of which the last $20 \mathrm{yr}$ were shown. In the CMIP3 multimodel mean, there is a peak in top-to-bottom $\mathrm{OHU}$ at $40^{\circ} \mathrm{S}$, which is spread over a wide range of longitudes. In addition, the Atlantic evidently warms much more than the Pacific. The OHU in our simulations is similar to the CMIP3 model mean in both the Southern Ocean maximum and the warmer Atlantic Ocean. The OHU peak at $40^{\circ} \mathrm{N}$ in our simulations, however, does not appear in the CMIP3 model mean. This is probably related to the time period we use in our simulations (70-yr mean); a progressive equatorward advection of the warming occurring at the extratropics in our simulations results in strong warming in the subtropics during the last decades of the simulations (not shown), as in the CMIP3 model mean, masking the relative importance of the northern latitudes as a region of heat entrance into the ocean.

The zonal distributions of the depth integrated heat flux convergences (Fig. 5) reveal which heat transport processes are causing OHU at each location. All the components are associated with vertical fluxes, except for ADV and EIA/EHF, which include also fluxes along the horizontal direction. We discuss these convergences separately for the northern $\left(30^{\circ}-90^{\circ} \mathrm{N}\right)$, southern $\left(30^{\circ}-\right.$ $\left.90^{\circ} \mathrm{S}\right)$, and tropical latitudes $\left(30^{\circ} \mathrm{S}-30^{\circ} \mathrm{N}\right)$.

The contributions of the various processes to the $120 \mathrm{~m}$-bottom OHU of each model are summarized in Fig. 6 (right $y$ axis, separated into the northern, tropical, and southern latitude bands). The left $y$ axis of Fig. 6 shows the changes in heat fluxes caused by the ocean heat transport processes, normalized by each model's sea surface temperature change.

This quantity is similar to the usual ocean heat uptake efficiency (e.g., Kuhlbrodt and Gregory 2012), which is however calculated from a $1 \% \mathrm{yr}^{-1} \mathrm{CO}_{2}$ forcing scenario (rather than abrupt $4 \times \mathrm{CO}_{2}$ ) and normalized by the model's global-mean surface air temperature change (including land areas); we normalize by SST change because of our focus on ocean processes. This quantity allows us to evaluate (approximately, because of the different scenario and normalization) the contributions of different processes to ocean heat uptake efficiency in three models. All three models, for example, seem to 

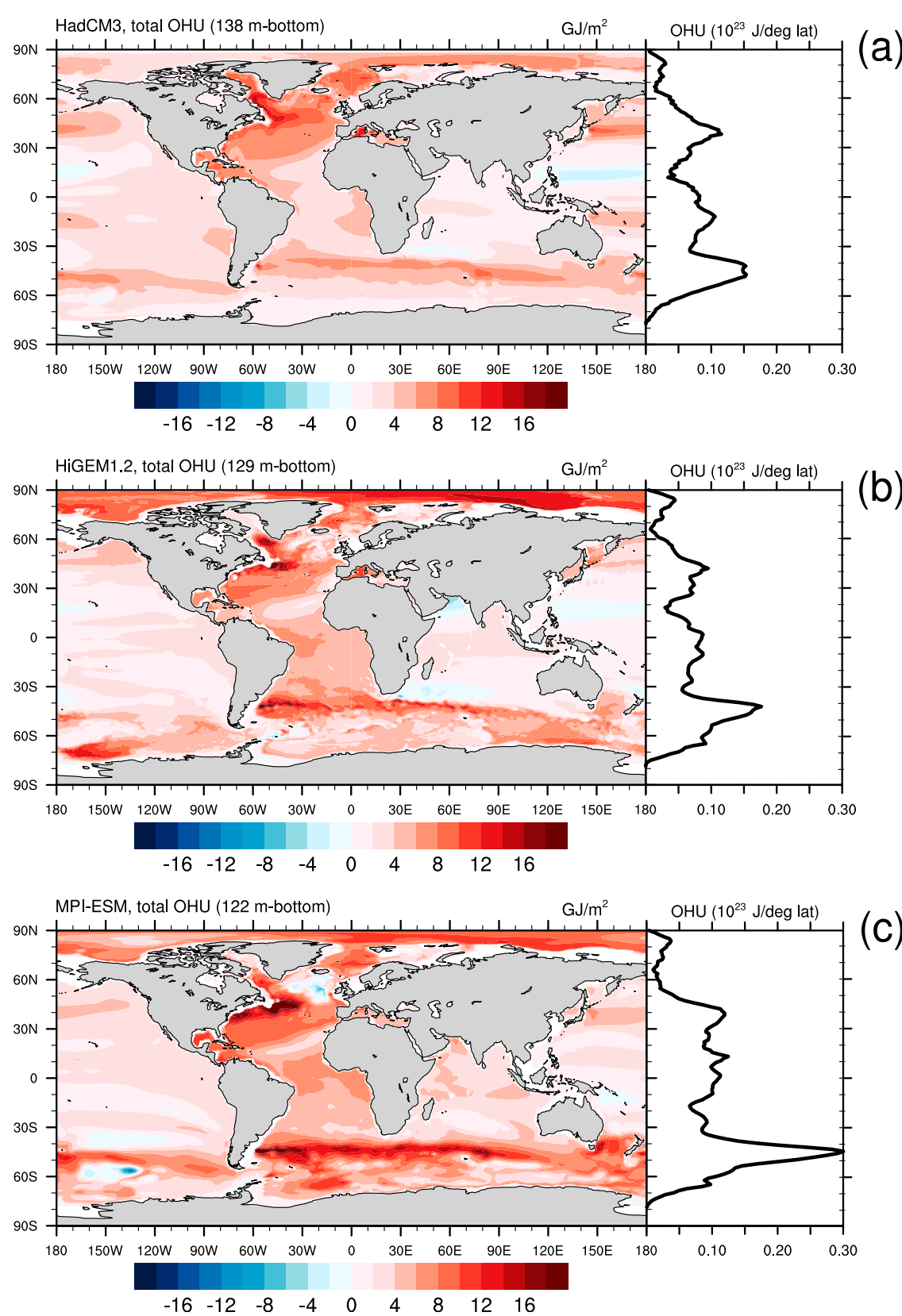

FIG. 4. Maps show ocean heat uptake $\left(\mathrm{GJ} \mathrm{m}^{-2}\right.$; time mean of years $\left.1-70\right)$, vertically integrated from $120 \mathrm{~m}$ to the bottom (subject to each model discretization), for (a) HadCM3, (b) HiGEM1.2, and (c) MPI-ESM. The line plots on the right-hand side show the zonally integrated ocean heat uptake $\left(10^{23} \mathrm{~J}^{\circ} \mathrm{lat}^{-1}\right)$ for the corresponding model.

have very comparable OHU efficiencies, as well as very comparable contributions to the OHU efficiencies from the three zonal bands, with HadCM3 slightly lower than the other two models.

\section{c. Southern latitudes}

The OHU in the Southern Ocean is strong and accounts for about $35 \%$ of the $120 \mathrm{~m}$-bottom OHU in HiGEM1.2 and MPI-ESM, contained within $30 \%$ of the $120 \mathrm{~m}$-bottom ocean volume (Fig. 6). Also, in these two models the Southern Ocean is the dominant region for OHU below $2000-\mathrm{m}$ depth, and it accounts for about $8 \%-11 \%$ of the $120 \mathrm{~m}$-bottom OHU. In HadCM3, the OHU in the Southern Ocean is somewhat weaker (about $30 \%$ of its $120 \mathrm{~m}$-bottom OHU). Below $2000 \mathrm{~m}$ the OHU is particularly weak, about $3 \%$ of the $120 \mathrm{~m}$-bottom OHU: 

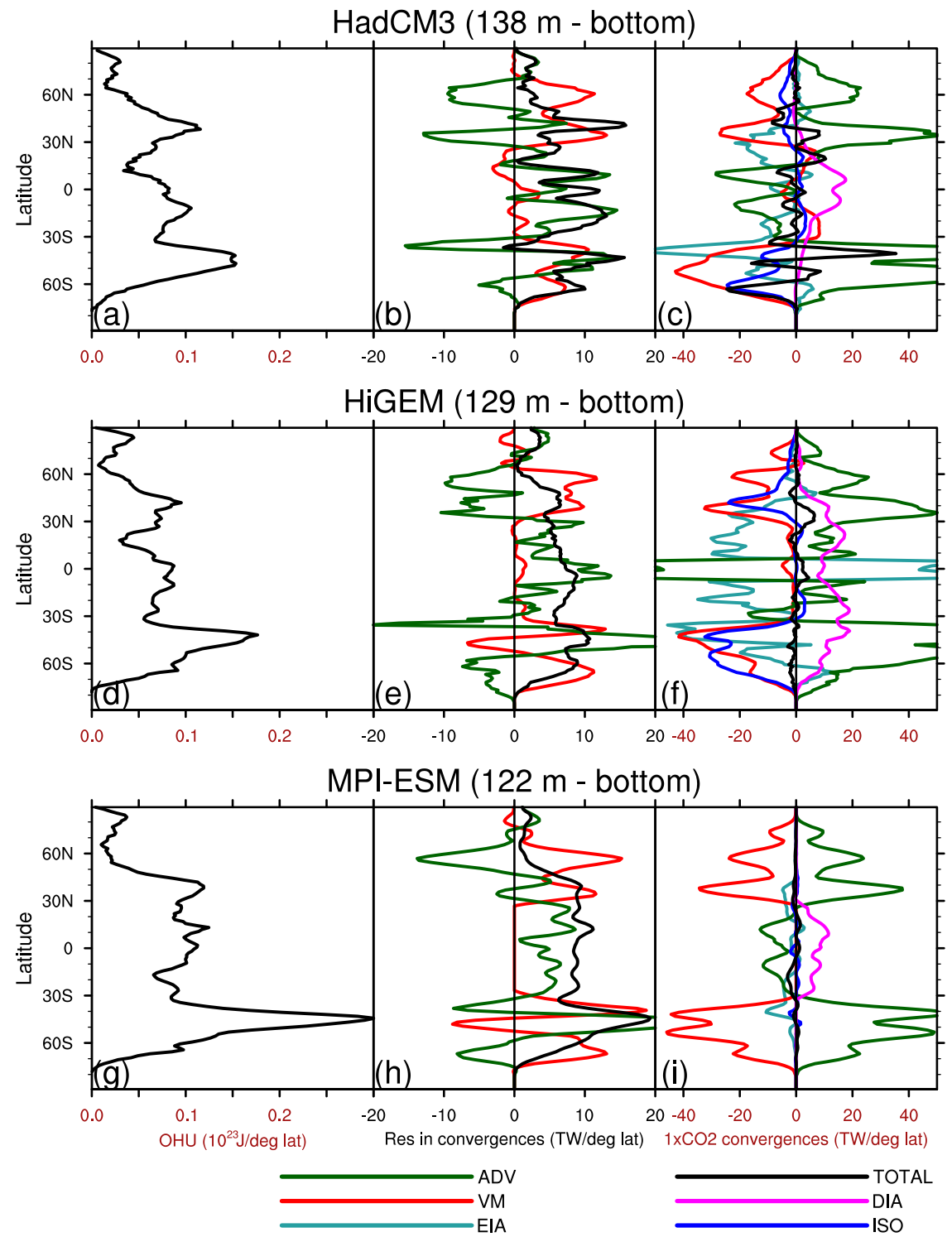

FIG. 5. (left) Zonally and depth integrated ocean heat uptake $\left(10^{23} \mathrm{~J}^{\circ} \mathrm{lat}^{-1}\right.$ ) (as on rhs in Fig. 4). Zonally and depth integrated heat flux convergences ( $\mathrm{TW}^{\circ} \mathrm{lat}^{-1}$ ) for (center) the responses and (right) the $1 \times \mathrm{CO}_{2}$ climate [(right) is as in Fig. 2]. In (center), only the three largest terms are shown for clarity (VM, ADV, and TOT). The depth integrations are from $120 \mathrm{~m}$ to the bottom (subject to models' discretization), and they are time-means for years 1-70. The light-blue line (EIA in legend) in HiGEM1.2 denotes the EHF. MPI-ESM and HiGEM1.2 data are interpolated onto HadCM3 grid. A 5-point running mean has been applied in the convergences of all three models, except for the advective, eddy advective, and total terms of HiGEM1.2 [green, light-blue, and black lines in (e) and (f)], where a 10-point running mean has been applied instead. The terms ADV and EIA/EHF also include components along the $y$ direction, whereas all the other terms contain only $z$-direction components.

most of which takes place in the Southern Ocean (Fig. 6d).

The peak warming in all three models is located at about $40^{\circ}-50^{\circ} \mathrm{S}$, and it is particularly strong in MPI-ESM, almost double (Figs. 5a,d,g). The warming is relatively strong over a thin zonal band at about $45^{\circ} \mathrm{S}$ in all three models. In
HiGEM1.2 the warming pattern has a "patchy" appearance (Fig. 4b), reflecting its partly resolved eddy structure. Additional warming occurs in the Weddell Sea in MPIESM and near the Ross Sea in MPI-ESM and HiGEM1.2. Any warming occurring poleward of $60^{\circ} \mathrm{S}$ in these two models is mostly due to strong OHU below $2000 \mathrm{~m}$. 
(a) From 138-bottom, $\mathrm{HadCM} 3$

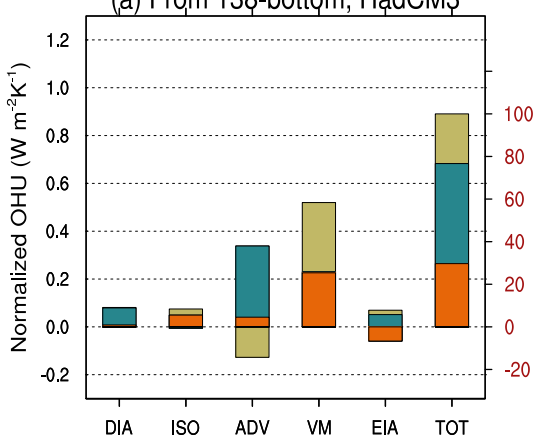

(d) From 2116-bottom, HadCM3

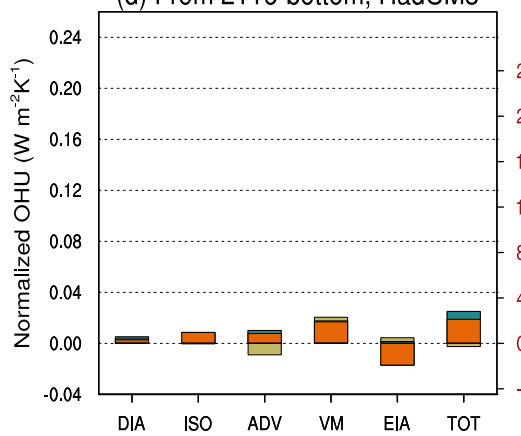

(b) From 129-bottom, HiGEM1,2

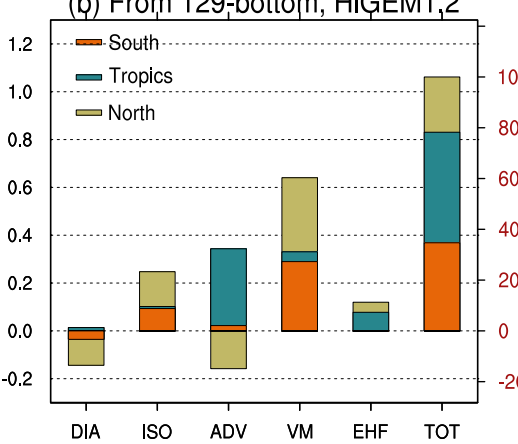

(e) From 2131-bottom, HiGEM1.2

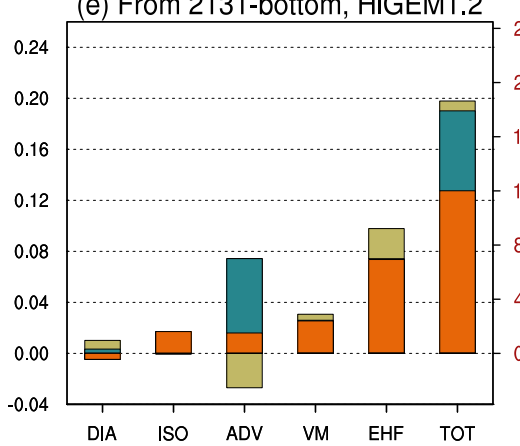

(c) From 122-bottom, MPI-ESM

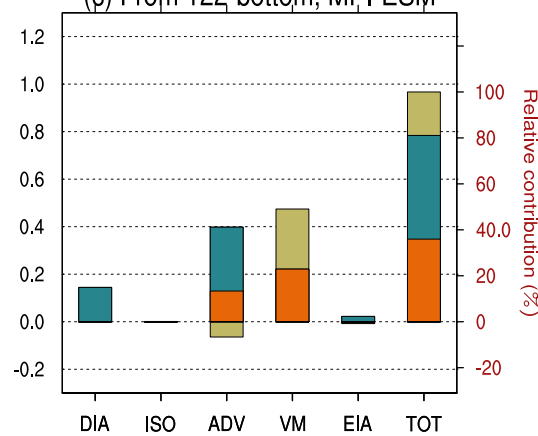

(f) From 2080-bottom, MPI-ESM

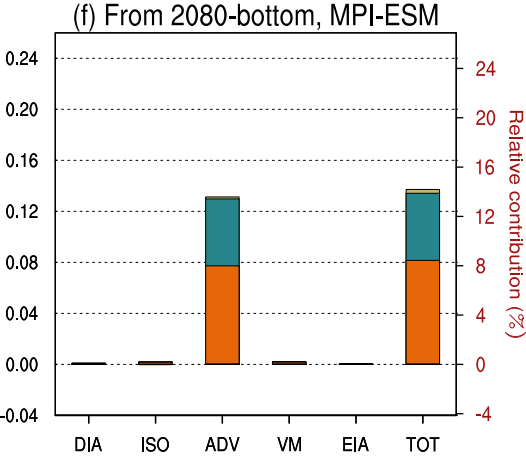

FIG. 6. The values on the left axis denote the changes in heat fluxes caused by the ocean heat transport processes (time means of years 1-70) normalized by each model's sea surface temperature change at year $70\left(\mathrm{~W} \mathrm{~m}^{-2} \mathrm{~K}^{-1}\right)$. The horizontal grid corresponds to the left axis values. For calculating the fluxes, we divide by the area of the surface ocean in all cases; therefore, the sum of the bars represents the total change (right-hand bar labeled TOT). The values on the right axis denote the relative contributions (\%) of each process to the total ocean heat uptake [always summing up to $100 \%$ for TOT in (top)]. Different colors denote contributions from different latitude belts, where north is $30^{\circ}-90^{\circ} \mathrm{N}$, tropics is $30^{\circ} \mathrm{S}-30^{\circ} \mathrm{N}$, and south is $30^{\circ}-90^{\circ} \mathrm{S}$. Results are shown for (a)-(c) the total water column (where "total" here denotes from $120 \mathrm{~m}$ to bottom, subject to models' discretization) and (d)-(f) from $2000 \mathrm{~m}$ to bottom for (left) HadCM3, (center) HiGEM1.2, and (right) MPI-ESM.

HadCM3, which has weak OHU below $2000 \mathrm{~m}$, also has very weak $120 \mathrm{~m}$-bottom OHU poleward of $60^{\circ} \mathrm{S}$ (Fig. 4a).

The most important process that leads to Southern Ocean warming is reduction in cooling from VM. It accounts for about $70 \%-100 \%$ of the Southern Ocean warming (Fig. 6). VM changes have a peak at both midlatitudes (at about $40^{\circ} \mathrm{S}$ ) and high latitudes (poleward of $60^{\circ} \mathrm{S}$; Figs. 5b,e,h). The VM peak poleward of $60^{\circ} \mathrm{S}$ is mostly associated with reduction in convection over the major deep-water formation locations near the Weddell Sea, the Ross Sea, and the Antarctic coast. However, the largest part of the vertical mixing changes, mostly at midlatitudes, is associated with wind-driven changes in the turbulent vertical mixing within the mixed layer. All three models show a shift and a strengthening of the westerlies at these latitudes (not shown). In particular, all three models show a strong strengthening of the zonal wind stress centered at about $55^{\circ} \mathrm{S}$ and a weakening (with weaker magnitude than the strengthening) centered at about $35^{\circ} \mathrm{S}$. This response is common among most climate models (e.g., Fyfe and
Saenko 2006; Sen Gupta et al. 2009). The shift and strengthening of the westerlies strengthen the cooling caused by mixed-layer vertical mixing near $50^{\circ} \mathrm{S}$ (except for HadCM3) but weaken the mixed-layer cooling (causing warming) at $35^{\circ} \mathrm{S}$ (in all three models; Figs. 5b,e,h). The weaker magnitude of VM responses in the Southern Ocean in HadCM3 is related to its wind stress changes. The strengthening of HadCM3 wind stress is significantly weaker than HiGEM1.2 (by a factor of 2) and MPI-ESM (by a factor of 3).

The peak warming at $45^{\circ} \mathrm{S}$ is caused by ADV. We postulate that part of the advective warming is related to the change in the wind-driven circulation, which in turn results from a shift and a strengthening of the westerlies at these latitudes. The surface westerlies at midlatitudes and easterlies at subtropics cause northward and southward Ekman drifts, which result in mass and heat convergence at about $40^{\circ}-45^{\circ} \mathrm{S}$ and in downwelling of warm water masses in the deeper ocean. The shift and strengthening of the westerlies also cause a corresponding shift and strengthening of the advective convergences, 
resulting in the strong warming in the convergence zone near $45^{\circ} \mathrm{S}$ but also in the weaker cooling northward and southward of the convergence zone (at $30^{\circ} \mathrm{S}$ and poleward of $60^{\circ} \mathrm{S}$ in Figs. 5b,e, h).

The only other process that contributes to warming of the Southern Ocean is changes in ISO. Changes in ISO take place in both HiGEM1.2 and HadCM3, which have very similar settings in their isopycnal formulation (Table 2). In MPI-ESM, as mentioned above, isopycnal diffusion plays no significant role in OHU (appendix B). Changes in DIA have a cooling effect in the Southern Ocean of HiGEM1.2. Their cooling effect in $4 \times \mathrm{CO}_{2}$ is likely exaggerated as a result of our indirect method of calculating them with POTTE (discussed in appendix A). Changes associated with eddies (EIA/EHF) are different among all three models. In particular, they cause cooling in HadCM3, and they have no significant net impact in HiGEM1.2 and MPI-ESM (Fig. 6). In HiGEM1.2, the EHF have a warming effect below $2000 \mathrm{~m}$, balanced by a cooling effect above $2000 \mathrm{~m}$, hence resulting in the negligible net impact (Fig. 6b). In MPI-ESM, the EIA responses are weak because of the small thickness diffusion coefficients in the numerical formulation (Table 2).

The weaker OHU in HadCM3, particularly the very weak OHU below $2000 \mathrm{~m}$ in the Southern Ocean, thus seems to be associated with its weaker response in the zonal wind stress. Both VM and ADV, which are the two dominant processes in Southern Ocean warming, are in large part wind-related responses, through wind-driven vertical mixing and Ekman pumping. An additional cause is related to the HadCM3 having initially strong stratification, which weakens its VM processes. Moreover, the weak deep Southern Ocean warming in HadCM3 also seems to be associated with its weaker warming in the Atlantic. The time evolution of the OHU (not shown) reveals that the Atlantic warming in HiGEM1.2 and MPI-ESM seems to originate from the deep Southern Ocean, where it is advected northward with the deep AABW flow. Longer simulations result in warmer subtropics that resemble the CMIP3 multimodel zonal mean (Kuhlbrodt and Gregory 2012).

\section{d. Tropical latitudes}

The tropical latitudes account for about $45 \%-50 \%$ of the $120 \mathrm{~m}$-bottom ocean volume and hold about $45 \%$ of the $120 \mathrm{~m}$-bottom OHU (Fig. 6). In the first years of the simulations, the OHU in the tropics is considerably weaker, whereas the OHU in the Southern Ocean is stronger than the 70-yr mean (not shown). Even though we cannot separate horizontal from vertical components in ADV, it seems plausible that part of the tropical warming is horizontally advected with time from the Southern Ocean to the tropics. Such a hypothesis is supported by ADV being the dominant term in the tropics in Figs. 5b,e,h and 6. Part of this horizontal advection of heat in HiGEM1.2 and MPI-ESM is possibly conveyed in the deep ocean with the AABW flow, as also hypothesized above. In these models, $5 \%-6 \%$ of their $120 \mathrm{~m}$-bottom OHU occurs below $2000 \mathrm{~m}$ in the tropics (Figs. 6e,f). In addition, part of the warming in the tropics could be occurring from horizontal advection of heat from the northern latitudes, as the cooling ADV in the north suggests (Figs. 6a-c). This warming could be interpreted as reduced poleward advection of warm waters and equatorward advection of cold waters, resulting from the reduction of the overturning circulation (not shown).

A second cause of warming in the tropics is a strengthening of diapycnal diffusion. DIA in the tropics contributes about $5 \%-15 \%$ of the $120 \mathrm{~m}$-bottom OHU in HadCM3 and MPI-ESM (Fig. 6). DIA causes warming because of a stronger stratification in the tropics in the $\mathrm{CO}_{2}$-perturbed climates, which in turn is caused by the surface warming. A weak contribution to OHU in the tropics in HadCM3 and HiGEM1.2 also originates from changes in EIA/EHF, implying reduced eddy-related cooling.

\section{e. Northern latitudes}

The northern latitudes, which account for about $13 \%$ of the $120 \mathrm{~m}$-bottom ocean volume, contribute about $20 \%$ to $120 \mathrm{~m}$-bottom OHU, mostly above $2000 \mathrm{~m}$ (Fig. 6). The northern OHU in all three models is almost entirely caused by VM. Vertical mixing changes cause two peaks of warming located at about $40^{\circ}$ and $60^{\circ} \mathrm{N}$ that are both opposed by advective cooling. The vertical mixing peak at $60^{\circ} \mathrm{N}$ is mostly associated with reduction in convection over the Labrador Sea or the Nordic seas, where models have strong convection during their control climates. HiGEM1.2 has particularly deep convection in Labrador Sea that reaches below $2000 \mathrm{~m}$ in $1 \times$ $\mathrm{CO}_{2}$, which is being reduced in the $4 \times \mathrm{CO}_{2}$ climate at large depths, hence creating a deep OHU maximum at $60^{\circ} \mathrm{N}$ (not shown). The peak near $40^{\circ} \mathrm{N}$ is associated with reduced cooling from reduced wind-driven vertical mixing, because of a reduction in the wind stress curl at this location, which is a also a feature of CMIP multimodel-mean wind stress curl (Bouttes et al. 2012).

Changes in ADV mostly cool the ocean between $30^{\circ}$ and $60^{\circ} \mathrm{N}$ but warm it between $60^{\circ}$ and $90^{\circ} \mathrm{N}$ (Fig. 5). More specifically, advective warming decreases between $30^{\circ}$ and $60^{\circ} \mathrm{N}$ (reducing OHU) but increases at $60^{\circ} \mathrm{N}$ (enhancing $\mathrm{OHU}$ ), but the net effect in the northern latitudes is a cooling one (Fig. 6). The decrease in advective warming between $30^{\circ}$ and $60^{\circ} \mathrm{N}$ is related to horizontal transports and a result from the reduction in 
overturning circulation (not shown), seen in all three models, that causes weaker transport of warm water poleward. The increase in advective warming between $60^{\circ}$ and $90^{\circ} \mathrm{N}$, which appears in all three models, is likely related to an increase in northward transport of North Atlantic water, caused by a strengthening of the overturning circulation in northern North Atlantic and Arctic Ocean, as suggested by Bitz et al. (2006). The strengthening of the circulation, in turn, is suggested to be related to increasing convection along the Siberian shelves, caused by increase in ice production and ocean surface heat loss in the Arctic basin. In our simulations, there is indeed an increase in convection in the Arctic Ocean in HadCM3 and HiGEM1.2 and east of Greenland coast in MPI-ESM (not shown).

Another process that contributes to OHU in HadCM3 and HiGEM1.2 is reduced ISO cooling, due to changes in isopycnal temperature gradients, as discussed above. Reduced ISO cooling at northern latitudes is responsible for about $3 \%-13 \%$ of $120 \mathrm{~m}$-bottom OHU in HadCM3 and HiGEM1.2. This process is absent in MPIESM, as discussed before. Finally, changes in northern EHF in HiGEM1.2 contribute to about $4 \%$ of its $120 \mathrm{~m}-$ bottom OHU, whereas eddies play no significant role in $\mathrm{OHU}$ in the northern latitudes of the other two models.

\section{Differences among models in advection}

The responses in advective heat flux convergences, as discussed in section 6 , are the second most important warming process contributing to OHU (Fig. 6). If advective heat convergence in $4 \times \mathrm{CO}_{2}$ is equal to $-\nabla \cdot[(\mathbf{u}+$ $\left.\left.\mathbf{u}^{\prime}\right)\left(\theta+\theta^{\prime}\right)\right]$, where $\mathbf{u}$ and $\theta$ are velocities and temperatures from $1 \times \mathrm{CO}_{2}$ and $\mathbf{u}^{\prime}$ and $\theta^{\prime}$ are the responses (defined as the differences between $4 \times \mathrm{CO}_{2}$ and $1 \times \mathrm{CO}_{2}$ ), then the global-mean responses in ADV are

$$
\begin{aligned}
\int_{H} & \left\{-\nabla \cdot\left[\left(\mathbf{u}+\mathbf{u}^{\prime}\right)\left(\theta+\theta^{\prime}\right)\right]+\nabla \cdot(\mathbf{u} \theta)\right\} \\
= & \int_{H}-\nabla \cdot\left(\mathbf{u} \theta^{\prime}+\mathbf{u}^{\prime} \theta+\mathbf{u}^{\prime} \theta^{\prime}\right)=-\frac{\partial}{\partial z}\left(w \theta^{\prime}+w^{\prime} \theta+w^{\prime} \theta^{\prime}\right),
\end{aligned}
$$

where in the global horizontal means the $u$ and $v$ components are zero because of the boundary conditions and only the vertical velocity $w$ remains. According to Eq. (2), changes in advective heat flux convergences can be decomposed into the convergences related to three different contributions: the changes in the temperature field without considering the changes in circulation (i.e., addition of heat; $\left.w \theta^{\prime}\right)$, the changes in the circulation without considering the changes in temperature (i.e., redistribution of heat; $w^{\prime} \theta$ ), and the advective changes caused by both the anomaly temperature and anomaly circulation (i.e., nonlinear change in advection of heat; $w^{\prime} \theta^{\prime}$ ). POTTE (appendix A) allows us to calculate offline estimates of the heat flux convergences arising from addition of heat and redistribution of heat, by estimating what the advection would be if velocities are the same as in the $4 \times \mathrm{CO}_{2}$ climate and temperatures the same as in the $1 \times \mathrm{CO}_{2}$ climate or vice versa (Fig. 7). We can have confidence that POTTE can give accurate estimations of the above terms, because POTTE can closely reproduce the online advective diagnostics in HadCM 3 and MPIESM (i.e., the light-green curves are very close to the dark-green curves in Figs. 7a,c).

The responses in heat flux convergences arising from addition of heat $\left[-\partial\left(w \theta^{\prime}\right) / \partial z\right]$ are qualitatively very similar among the models, in the sense that all models show a strong warming near the surface (below $130 \mathrm{~m}$ in HiGEM1.2 and MPI-ESM and below $300 \mathrm{~m}$ in HadCM3) that decays with depth (blue curves in Fig. 7). That comes as no surprise since the additional heat enters the ocean through the sea surface.

There are common features but also important differences in the responses in heat flux convergences arising from redistribution of heat $\left[-\partial\left(w^{\prime} \theta\right) / \partial z\right]$ among the models. Strong negative convergences close to the surface are compensated by the positive convergences below a certain depth (about $1200 \mathrm{~m}$ in HadCM3 and HiGEM1.2 and $400 \mathrm{~m}$ in MPI-ESM), implying a top-to-bottom redistribution of heat through changes in circulation alone (magenta curves in Fig. 7). This redistribution is related to a strengthening of the winddriven circulation and a deepening of the Ekman layer, caused by a strengthening of the westerly winds (Fyfe and Saenko 2006; Sen Gupta et al. 2009). The warming due to the redistribution of heat, however, in HadCM3 is small and occurs only between about 1200 and $2000 \mathrm{~m}$ and in HiGEM1.2 is significant (but also small) only between 1200 and $1800 \mathrm{~m}$ and below $3500 \mathrm{~m}$. In MPI$\mathrm{ESM}$, on the other hand, the redistribution term is very strong and is the largest term of the decomposition below $800 \mathrm{~m}$, implying that changes in circulation are more effective in causing OHU than the addition of heat in the ocean in MPI-ESM. This result is consistent with MPIESM having the strongest increase (by a factor of 2 or 3 compared to the other two models) of the westerly winds over the Southern Ocean.

In addition, the result is also consistent with the overturning circulation responses in MPI-ESM being also much stronger than in the other two models, causing, therefore, stronger redistribution of heat to the deeper ocean. The overturning circulation responses in all three models is a general reduction of the overturning 

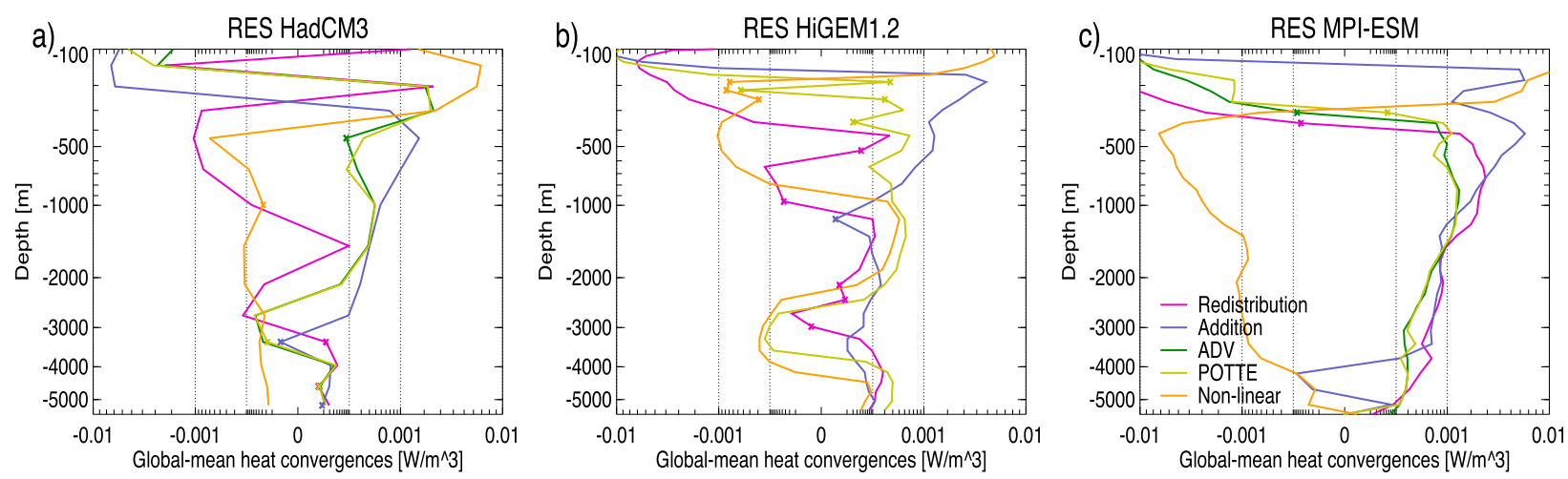

FIG. 7. POTTE-derived emulations of the responses in global-mean advective heat flux convergences caused by addition of heat $\left[-\partial\left(w \theta^{\prime}\right) / \partial z\right]$, redistribution of heat $\left[-\partial\left(w^{\prime} \theta\right) / \partial z\right]$, and the nonlinear advective term $\left[-\partial\left(w^{\prime} \theta^{\prime}\right) / \partial z\right]\left(\mathrm{W} \mathrm{m}{ }^{-3}\right)$ for $(\mathrm{a}) \mathrm{HadCM} 3$, (b) HiGEM1.2, and (c) MPI-ESM. The online ADV diagnostic is also shown (dark green), as well as the POTTE-derived advective diagnostic (light green), which serves as an evaluation metric of POTTE performance. HiGEM1.2 does not have online diagnostic for mean circulation but only for the residual. The axes are scaled by a power law. Dotted lines indicate orders of magnitude. Starred points denote statistically insignificant responses, defined as the responses where their absolute value is smaller than the $\pm 2 \sigma$ range $(\sigma$ is temporal standard deviation of heat convergences, calculated from the 70-yr means of the convergences in the total length of the control simulations).

strength, which is related to the reduction of deep-water formation in high latitudes caused by the increase in surface heat/freshwater fluxes. Previous studies demonstrated that models with stronger overturning circulation in their control state tend to show a stronger reduction in the overturning circulation (e.g., Gregory et al. 2005; Rugenstein et al. 2013). Therefore, the stronger reduction in MPI-ESM circulation may be related to its stronger Atlantic meridional overturning circulation (AMOC) in the control state, at least compared to HadCM3, whereas it is comparable in magnitude with the AMOC in HiGEM1.2.

The global-mean profile of the nonlinear term $\left[-\partial\left(w^{\prime} \theta^{\prime}\right) / \partial z\right]$ is qualitatively consistent among the three models, where it is mostly positive close to the surface but mostly negative below a relatively shallow depth in all models (in HiGEM1.2 the residual term is positive above $140 \mathrm{~m}$ but also between 1000 and $2000 \mathrm{~m}$ ). It has much larger magnitude in MPI-ESM than in the other two models. The large magnitude of this term in MPI-ESM implies that there are spatially correlated changes in $w$ and $\theta$, likely to be related to the overturning circulation. The upward heat fluxes caused by the nonlinear term (orange curves in Fig. 7) imply either anomalous upward transport of warmed waters or anomalous downward transport of cooled waters. The change of the sign of this term at a shallow depth indicates that it is related to the wind-driven circulation. A probable cause could be that the enhanced wind stress also causes enhanced upwelling in the subpolar regions, which, if occurring mostly in the Southern Ocean, would be associated with transport of warmer water masses to the colder surface, hence causing upward heat fluxes and cooling.

\section{Conclusions}

In our study, we have investigated and compared control and $\mathrm{CO}_{2}$-perturbed experiments (forced with abrupt $4 \times \mathrm{CO}_{2}$ ) performed with three different global climate models: HadCM3, HiGEM1.2, and MPI-ESM. We have analyzed the heat balances, as well as the response of the heat balances to $\mathrm{CO}_{2}$ perturbation, by means of the process diagnostics of the temperature equation, which are available on each model grid point. Such diagnostics represent how the convergence of heat flux is determined by heat uptake and transport processes.

We find that, in the global-mean control climates, there is no simple upwelling-diffusion balance. While such a balance holds for the subtropics, the global-mean balance is maintained between warming caused by diapycnal diffusion and advection by the mean circulation and cooling caused by vertical mixing processes and eddy-related processes (eddy-induced advection and isopycnal diffusion). Furthermore, the global-mean heat balance is dominated by the extratropics (particularly the Southern Ocean), where fluxes from vertical mixing processes, eddies, and the mean circulation play a dominant role. The diagram in Fig. 8 gives a schematic overview of the heat transport processes and their responses as a function of latitude.

In the zonal mean, heat is transported downward in the tropics (where solar forcing is strong) through diapycnal diffusion and in the midlatitudes of both hemispheres through wind-induced Ekman downwelling of warm surface waters. The warm masses are further advected poleward by the meridional circulation, 

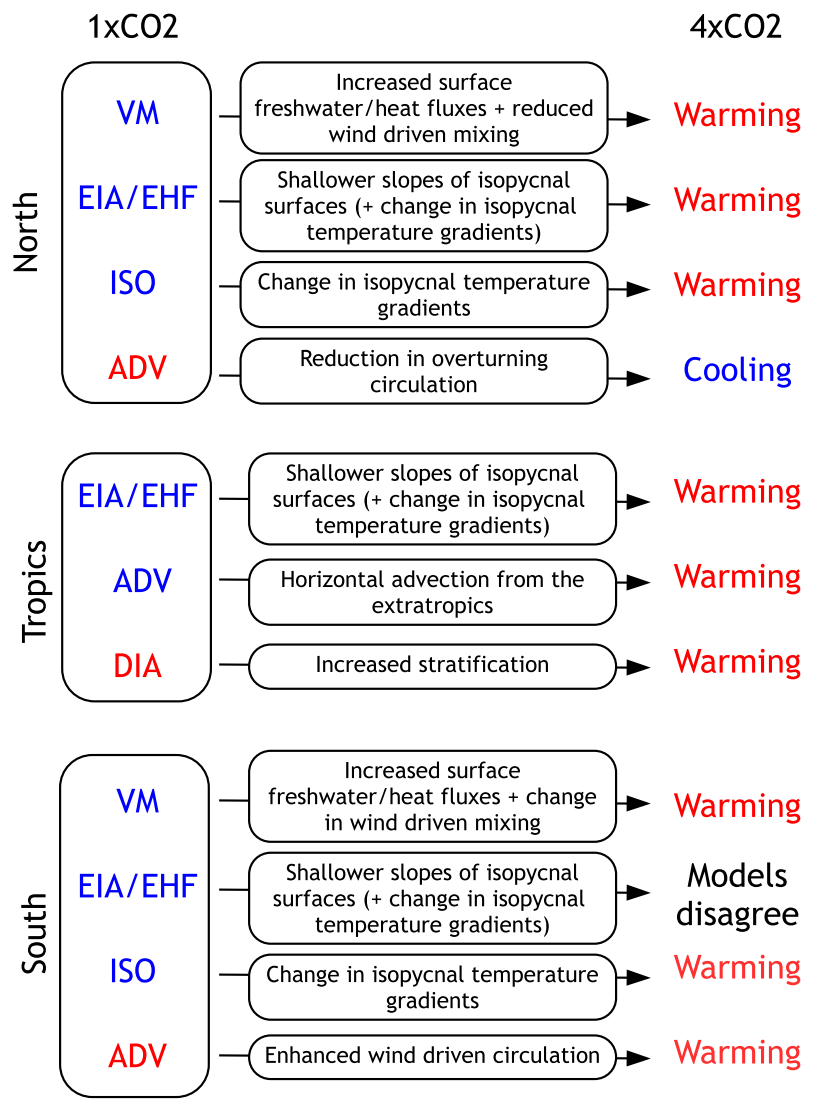

FIG. 8. Diagram describing the heat transport processes (in a zonal-mean sense, as a function of latitude) and whether they have a warming (red) or a cooling (blue) effect in $1 \times \mathrm{CO}_{2}$ climate and in their responses to abrupt $4 \times \mathrm{CO}_{2}$ forcing. A warming response to $\mathrm{CO}_{2}$ forcing could arise from a strengthening of a warming process or a weakening of a cooling one and vice versa.

leading to strong advective warming at high latitudes. Heat is transported upward at middle and high latitudes through eddy-related processes and vertical mixing. Wind-forced vertical mixing at midlatitudes and buoyancy-forced convective vertical mixing at high latitudes (due to either surface heat loss or surface salt gain from brine rejection) mix deeper warmer waters with colder surface waters, thus transporting heat to the surface. Eddy activity, caused by baroclinic instabilities along steep isopycnals, further transports heat upward, either by flattening steep isopycnal surfaces or by isopycnally diffusing heat upward along isopycnal surfaces.

In the global-mean $\mathrm{CO}_{2}$-perturbed climates, we find that the major contributors to $\mathrm{OHU}$ are changes in vertical mixing processes and changes in advection caused by the mean circulation, which together account for about $80 \%$ or more of the OHU below $120 \mathrm{~m}$. Changes in convergences associated with diapycnal diffusion account for less than $15 \%$, which is important mostly closer to the surface, where stratification is strong. The contribution of diapycnal diffusion to OHU, therefore, is much weaker than sometimes assumed. The remaining $10 \%-15 \%$ of the OHU below $120 \mathrm{~m}$ is due to changes in convergences associated with isopycnal diffusion and/or eddy heat fluxes.

The tropical zonal band shows a greatly increased heat content in the $\mathrm{CO}_{2}$-perturbed climates. Part of this is caused by enhanced diapycnal diffusion due to stronger stratification. However, we find that $\mathrm{OHU}$ occurs mainly in the extratropics, particularly in the Southern Ocean, and part of the added heat is advected to the tropics, possibly with the deep AABW flow, which results in the Atlantic becoming increasingly warmer than the Pacific with time. An additional reason for the tropical warming is the reduction in the overturning circulation, which leads to reduction in the northward transport of warm waters, resulting in a warming of the tropics but a cooling of the northern latitudes.

The dominant process that leads to $\mathrm{OHU}$ in the extratropics is vertical mixing. Changes in vertical mixing are partly buoyancy driven and partly wind driven. At high latitudes, changes in buoyancy, through changes in surface freshwater and/or heat fluxes, reduce convective cooling, which leads to ocean warming. At midlatitudes, the reduction of wind stress reduces winddriven vertical mixing within the mixed layer, leading to ocean warming. The second largest contribution to $\mathrm{OHU}$ in the extratropics is changes in advection by the mean circulation. Enhanced westerlies cause enhanced Ekman pumping of warm waters, which leads to warming of the Southern Ocean.

We have further examined the role of advection in contributing to OHU by decomposing the advective heat flux convergences into the convergences related to three different contributions: the changes in the temperature field without considering the changes in circulation (addition of heat), the changes in the circulation without considering the changes in temperature (redistribution of heat), and the advective changes caused by both the anomaly temperature and anomaly circulation (nonlinear change in advection of heat). We find that the addition of heat accounts for a large part of the advective warming, particularly close to the surface, where the heat enters into the ocean. The redistribution of heat accounts for advective warming at larger depths. Changes in circulation, therefore, cause a top-to-bottom redistribution of heat, which is related to a strengthening of the wind-driven circulation caused by a strengthening of the westerlies over the Southern Ocean.

MPI-ESM exhibits notable qualitative differences in the contribution of subgrid-scale processes to the heat balance and OHU, compared to the other two models. We find that the insignificant contribution of eddy-induced 
advection in MPI-ESM is related to its small thickness diffusion coefficients. The insignificant contribution of isopycnal diffusion in MPI-ESM is due to the tapering scheme, which reduces the values of the isopycnal diffusion coefficient over steep slopes, which affects $30 \%-85 \%$ of the grid points. The tapering scheme used in HadCM3 and HiGEM1.2, on the other hand, affects only $9 \%-30 \%$ of the grid points. The disturbing implication is that qualitatively different behaviors result from difference choices over what might be regarded as details of numerical formulations. Similar concerns arise from differences in the numerical treatment of advection (appendix A).

Because of these differences in the formulation of MPIESM and the stronger stratification in HadCM3, the three models have considerably different OHU below $2000 \mathrm{~m}$, where it is caused by different combinations of processes. However, the majority of OHU is above $2000 \mathrm{~m}$, and these three models are quantitatively similar in their global ocean heat uptake efficiency and its breakdown among processes and as a function of latitude. The relatively small differences among them are partly due to different choice of parameters in schemes representing subgrid-scale processes and partly due to different simulated changes in wind stress, which affect both the winddriven overturning circulation and turbulent vertical mixing in the upper layers. It would be valuable to make similar process-based comparisons of atmosphere-ocean general circulation models (AOGCMs), which have a wider spread of ocean heat uptake efficiency than the three analyzed here.

Acknowledgments. We thank the three anonymous reviewers for their careful reviews and constructive comments. We also thank Jochem Marotzke and Helmuth Haak for their help in setting up the simulations with the MPI-ESM, and for providing the computer resources with which to carry out the simulations. The research leading to these results has received funding from the European Research Council under the European Community's Seventh Framework Programme (FP7/2007-2013) ERC Grant Agreement 247220, project "Seachange."

\section{APPENDIX A}

\section{Partial Ocean Temperature Tendency Emulator}

Table 2 summarizes information on availability of online diagnostics for each model. For some processes, the online diagnostics are not available. We construct approximations of these diagnostics using archived fields from each model, along with knowledge of the values of various parameters that were used in each simulation. To this end, offline equivalents of the advection, isopycnal, diapycnal, and eddy diffusion schemes used in HadCM3 have been implemented.

We refer to this software as the Partial Ocean Temperature Tendency Emulator (POTTE). POTTE routines use temperature and salinity fields to reconstruct time-dependent density surfaces, from which the alongslope diffusion, across-slope diffusion, and strength of the implied eddy advection from the Gent-McWilliams scheme can be deduced. The archived velocities and diagnosed diffusion/velocity components are then used with the ocean temperature field to infer the fluxes of heat between grid boxes, and thus obtain the rates of temperature change due to the individual ocean processes.

An example of POTTE usage is with HiGEM1.2, where there is no separate term for eddy advection. Instead, the resolved advection term in HiGEM1.2 contains both the eddy-induced transport and the mean transport (often called residual advection). We diagnose offline the difference between the online residual mean advection $\overline{\nabla \cdot(\mathbf{u} \theta)}$ (where the bar denotes time mean) and the mean transport $\overline{\nabla \cdot(\overline{\mathbf{u}} \bar{\theta})}$, computed with POTTE, where we have used annual-mean fields for $\overline{\mathbf{u}}$ and $\bar{\theta}$. The resulting term represents the convergences caused by eddy heat fluxes. As discussed in GWMM95, the EHF transport can be written as a $3 \times 3$ tensor that is a sum of a symmetric and a skew-symmetric component. The symmetric component is an isopycnal diffusion operator, whereas the skew-symmetric component is the eddy-induced advective transport, which is parameterized by the GM scheme in the other two models. At this point, we cannot provide an estimate of the actual contributions of the two components in the EHF term in HiGEM1.2, implying that the EHF term is not strictly equivalent to the GM eddy-induced advection terms of HadCM3 and MPI-ESM, but for simplicity (albeit with caution) we compare them in our analysis.

HadCM3 and HiGEM1.2 do not have separate diagnostics for the DIA and ISO terms of Eq. (1) but instead have one diagnostic for the total vertical diffusion, which is the sum of both isopycnal and diapycnal contributions. We infer DIA and ISO terms, therefore, using POTTE. In MPI-ESM there are not separate diagnostics for vertical mixing $(\mathrm{VM}=\mathrm{ML}+\mathrm{CON})$ and DIA, but there is instead one online diagnostic containing both. We assume that DIA is zero within the mixed layer (in order to separate DIA from ML, with the latter being parameterized as enhanced windinduced vertical diffusion) and derive an offline POTTE estimation for DIA, which is then subtracted from the online diagnostic in order to infer VM (Table 2). This calculation based on the above assumption, however, has an implication: it produces significant positive 
VM values in the subtropical regions. These values most likely denote DIA mixing within the mixed layer, rather than actual convection or mixed layer processes. We correct this problem by adding the positive VM values in the subtropical regions to DIA.

The accuracies of POTTE's offline diagnostics compared to what would be found with an online calculation are dependent both on the time resolution of the archived tracer and velocity fields of the original models and on how closely the individual processes within the models mirror the way that they are modeled in HadCM3. For example, tracer advection in HadCM3 is usually handled with a centered differencing scheme, and this is what has been implemented in POTTE. Anomalies between the POTTE reconstruction of the temperature tendencies due to advection and those from online diagnostics can be noted in HiGEM1.2, which uses a fourth-order differencing scheme, and the anomalies can be particularly large in the bottom layer, where HiGEM1.2 uses the upwind scheme to avoid instabilities. MPI-ESM, on the other hand, uses a weighted scheme of a centered difference scheme and an upstream scheme for steep fronts. Here, errors in the POTTE reconstruction appear in areas where steep fronts are likely to develop, related to MPI-ESM's use of the upstream scheme. An example of the accuracy of the POTTE reconstruction of advection, calculated with monthly-mean temperature and velocities, is shown in Fig. 7. Global horizontal means of reconstructed advection are generally adequately precise for the purpose of this paper.

In HiGEM1.2, we do not use POTTE for offline reconstructing DIA. Instead, we reconstruct ISO using POTTE, and DIA is calculated as the difference between the online diagnostic for total vertical diffusion and the offline ISO diagnostic. An implication is that POTTE overestimates ISO cooling, hence creating a spurious DIA warming at middle and high latitudes, as opposed to HadCM3 and MPI-ESM (Fig. 2). In addition, POTTE overestimates the reduction in isopycnal cooling and thus also overestimates the cooling due to DIA (Fig. 6b).

POTTE was not used in reconstructing MPI-ESM offline diffusion, because of critical dependence of the constructed diagnostic on the details of the scheme. To reduce errors, we used an offline script, instead, that was based on the online MPI-ESM code. The disturbing implication is that, if POTTE's reconstruction critically depends on choices of numerical implementations, then differences among models may also be critically influenced by numerics. The sensitivity of models simulations to numerics could potentially undermine the robustness of derived scientific conclusions.

Given the inevitable differences between model implementations and without diagnostic output at each model time step, a tool such as POTTE is not going to be able to perfectly reproduce the behavior of processes within the ocean models. POTTE's main function, however, is as a tool to aid qualitative understanding of the large-scale differences between model responses to a common forcing. For this purpose, the numerical accuracy of the information that we can obtain from POTTE is adequate.

\section{APPENDIX B}

\section{Differences among Models in Isopycnal Diffusion}

Even though all three models we analyze in this study parameterize isopycnal diffusion using the formulation of Griffies et al. (1998) (Table 2), they exhibit large differences in how important the isopycnal diffusion is in the $1 \times \mathrm{CO}_{2}$ heat budget, as well as in the responses of the heat budget to the $\mathrm{CO}_{2}$ increase (section 5). More specifically, in MPI-ESM, the vertical component of the isopycnal diffusion has a weak or no impact in $1 \times \mathrm{CO}_{2}$ and does not significantly contribute to the $\mathrm{OHU}$ (Figs. $3 \mathrm{c}$ and $6 \mathrm{f}$ ). In the other two models, on the other hand, the vertical component of the isopycnal diffusion cools the ocean in $1 \times \mathrm{CO}_{2}$ and therefore significantly reduces warming in the ocean in $4 \times \mathrm{CO}_{2}$. In the current appendix, we explore the causes of these differences.

The implementation of Griffies et al. (1998) is based on the diffusion scheme suggested by Redi (1982) and implemented by Cox (1974) in the Cox (1984) version of the Geophysical Fluid Dynamics Laboratory (GFDL) ocean model. The Cox (1974) scheme parameterizes isopycnal diffusion using the product of the isopycnal diffusion coefficient $A_{I}$ with a $3 \times 3$ diffusion tensor, which is rotated in the direction of isopycnal surfaces. In the rotated tensor, the slopes of the isopycnal surfaces are calculated at each model time step. The tensor is simplified by making the so-called small-slope approximation, where it is assumed that the horizontal density gradients are much smaller than the vertical density gradients. This approximation allows for fewer terms to be calculated in the diffusion tensor and is, therefore, preferable over the full tensor for saving computational cost. In regions where steep isopycnal slopes appear, such as regions near strong convection, the small-slope approximation does not hold. In addition, isopycnal mixing along steep slopes creates large vertical fluxes, which creates numerical complications because it can violate the Courant-Friedrichs-Lewy (CFL) criterion in the diffusion equation. This issue is discussed in detail in appendix C of Griffies et al. (1998).

To preserve numerical stability, different methods have been employed for the isopycnal scheme with the 

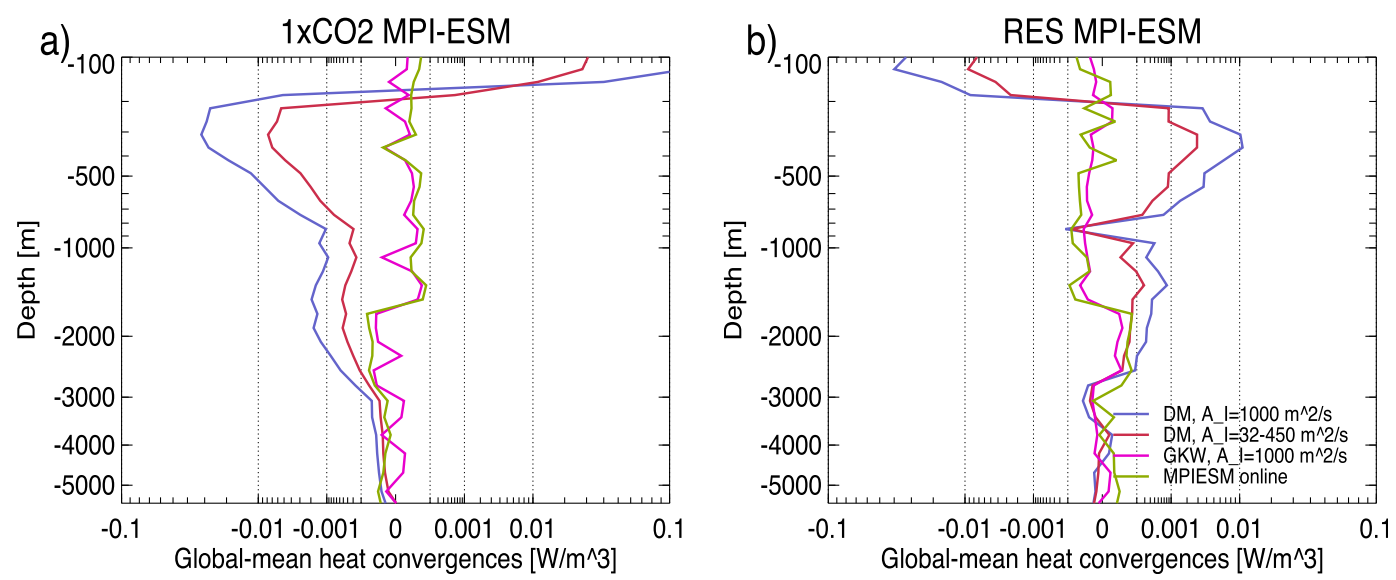

FIG. B1. Emulation of global-mean heat flux convergences caused by isopycnal diffusion $\left(\mathrm{W} \mathrm{m}^{-3}\right)$ for MPI-ESM temperature field using either the DM or GKW tapering scheme and different isopycnal diffusion coefficients for (a) $1 \times \mathrm{CO}_{2}$-MPI-ESM and (b) RES-MPI-ESM. The following combinations are shown: the DM scheme with the $\mathrm{A}_{I}$ equal to either the HadCM3 value (blue) or the MPI-ESM value (red) and the GKW scheme with the $\mathrm{A}_{I}$ equal to the HadCM3 value (magenta). Also shown is the actual online diagnostic (light green). The axes are scaled by a power law. Dotted lines indicate orders of magnitude.

small-scale tensor. One of these methods, introduced by Gerdes et al. (1991, hereafter GKW), reduces the isopycnal diffusion coefficient $A_{I}$ in steep slopes, by scaling it so that

$$
A_{I} \rightarrow A_{I}(\delta / S)^{2}
$$

when the isopycnal slope $|S|$ ( $S$ is either $S_{x}$ or $S_{y}$ ) becomes larger than a threshold value $\delta$. Another method, suggested by Danabasoglu and McWilliams (1995, hereafter DM), smoothly tapers $A_{I}$ to zero as $|S|$ increases above a critical value. The DM scheme uses a hyperbolic tangent function

$$
A_{I} \rightarrow 0.5 A_{I}\left[1-\tanh \left(\frac{|S|-\delta_{\mathrm{DM}}}{S_{\mathrm{DM}}}\right)\right]
$$

where $\delta_{\mathrm{DM}}$ is the slope at which $A_{I}=0.5 A_{I}$ and $S_{\mathrm{DM}}$ is the half-length of the interval in which the transition of $A_{I}$ to zero occurs.

MPI-ESM employs the GKW method [Eq. (B1), with $\left.\delta=0.02 \times d z^{2} / A_{I} d t\right]$. HadCM3 and HiGEM1.2, on the other hand, use the DM scheme [Eq. (B2)], with $\delta_{\mathrm{DM}}=$ 0.004 and $S_{\mathrm{DM}}=0.001$. In addition to the different tapering methods, the three models have different isopycnal diffusion coefficients $A_{I}$ values: HadCM3 uses $A_{I}=$ $1000 \mathrm{~m}^{2} \mathrm{~s}^{-1}$, whereas HiGEM1.2 uses $A_{I}=500 \mathrm{~m}^{2} \mathrm{~s}^{-1}$. In MPI-ESM the $A_{I}$ values are grid-size dependent and much lower, with $A_{I}=32-450 \mathrm{~m}^{2} \mathrm{~s}^{-1}$.

Two candidates, therefore, are the likely causes of the difference in the heat convergences by isopycnal diffusion among the three models in Fig. 3: the choice in the values of $A_{I}$ and the choice in tapering scheme. To explore the two different possibilities, we use the MPIESM temperature field in a FORTRAN-based script to emulate the model diffusion offline, whereby we can modify either $A_{I}$ values or the tapering scheme. We know that the FORTRAN-based script correctly emulates isopycnal diffusion because it successfully reproduces the online MPI-ESM isopycnal diffusion diagnostics with high accuracy. The results of the emulation of the offline diffusion, for both tapering schemes and for $A_{I}=1000 \mathrm{~m}^{2} \mathrm{~s}^{-1}$ or $A_{I}=32-450 \mathrm{~m}^{2} \mathrm{~s}^{-1}$, are shown in Fig. B1. Changing the coefficient to $A_{I}=$ $1000 \mathrm{~m}^{2} \mathrm{~s}^{-1}$ but keeping the GKW scheme does not significantly modify the MPI-ESM heat convergences (magenta line in Fig. B1). On the contrary, it even makes the magnitude smaller than the actual online convergences, which is counterintuitive, if we take into account that $A_{I}$ is more than doubled than its online value. We will explain below why this happens. However, if we use the DM tapering scheme, which is also used in HadCM3 and HiGEM1.2, the convergences are far more similar to the HadCM3 or HiGEM1.2 convergences, even with the relatively low MPI-ESM coefficients. In addition, changing $A_{I}$ to larger values when using the DM scheme strengthens the magnitude of the convergences. We discuss below the reasons behind these changes.

Both tapering schemes reduce the value of $A_{I}$ on steep slopes. The implication is that the vertical component of isopycnal diffusion on steep slopes is also reduced. Both schemes achieve this by reducing $A_{I}$ to zero while scaling it with a scaling factor that is a function of the slope $S$ [Eqs. (B1) and (B2)]. In addition, in the case of the 
GKW scheme, the scaling factor is also a function of the grid thickness $d z$ and $A_{I}$ (in the case that $A_{I}$ is not constant). We can compute the scaling factors for both schemes as a function of $S$, assuming a constant $A_{I}=$ $250 \mathrm{~m}^{2} \mathrm{~s}^{-1}$ in MPI-ESM (a reasonable average value for $A_{I}$ in MPI-ESM according to Table 2). Since in the GKW scheme there is a dependence on $d z$, we compute the scaling factor for three thicknesses, $d z=50,200$, and $400 \mathrm{~m}$, representative of gridcell thicknesses in depth ranges of $160-700 \mathrm{~m}, 1000-3000 \mathrm{~m}$, and $3000 \mathrm{~m}$-bottom, respectively. According to Fig. B2, in the GKW scheme at depths, for example, of 160-700 $\mathrm{m}$ where $d z \approx 50 \mathrm{~m}$, in any slope larger than the "cutoff" slope $S=10^{-4.5} \approx$ $3 \times 10^{-5}, A_{I}$ is reduced by up to several orders of magnitude. The cutoff slope, where the GKW scheme is activated, becomes larger with $d z$ and thus with depth and is equal to approximately $S \approx 10^{-3}$ or $S=10^{-2.5} \approx$ $3 \times 10^{-3}$ for the depth ranges of $1000-3000 \mathrm{~m}$ and $3000 \mathrm{~m}$-bottom, respectively. This means that the GKW scheme allows for steep slopes to develop at larger depths but drastically reduces $A_{I}$ in the presence of steep slopes at depths closer to the surface. The scaling factor in the DM scheme, on the other hand, not being a function of anything other than the slope $S$, has a single cutoff slope $S \approx 3 \times 10^{-3}$ for all depths and reduces much faster than in the GKW scheme. Overall, above $3000 \mathrm{~m}$, slopes smaller than $S \approx 3 \times 10^{-3}$ are unaffected by the DM scheme, whereas they are reduced by the GKW scheme. Below $3000 \mathrm{~m}$, both schemes are at work for slopes larger than $S \approx 3 \times 10^{-3}$.

To evaluate what part of the ocean is affected by the schemes at different depths, we examine what part of grid points have isopycnal slopes with values larger than the cutoff slopes of the two schemes at the corresponding

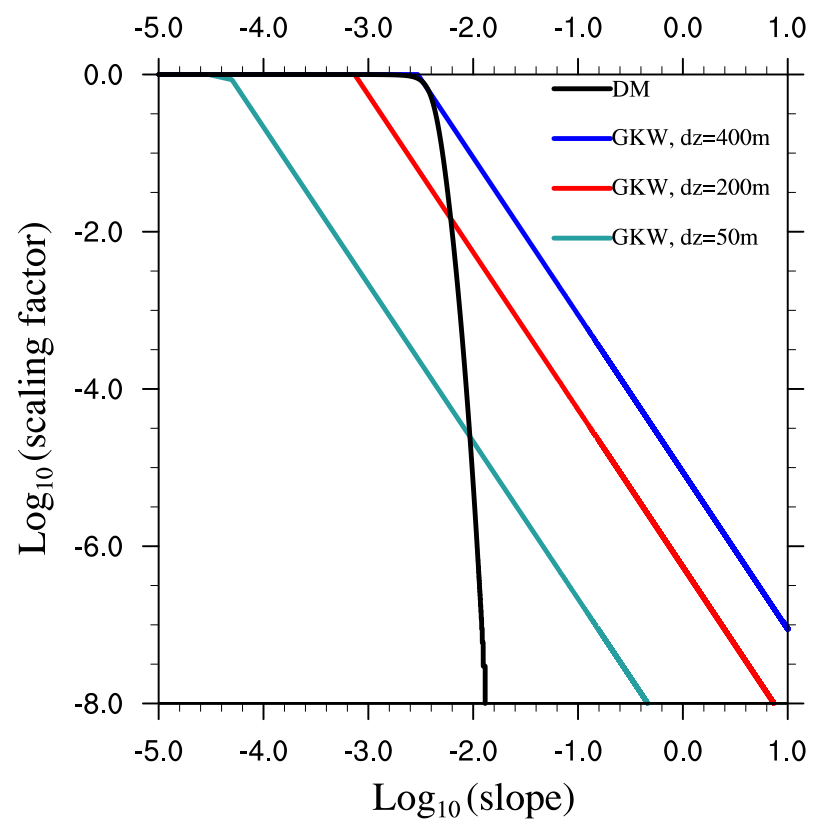

FIG. B2. Scaling factor as a function of the isopycnal slope (in logarithmic scales) for the GKW scheme [Eq. (B1)] with three different thicknesses, $d z=50,200$, and $400 \mathrm{~m}$ (representative of gridcell thicknesses in depth ranges $160-700 \mathrm{~m}, 1000-3000 \mathrm{~m}$, and $3000 \mathrm{~m}$-bottom, respectively), and the DM scheme [Eq. (B2)].

depths (Fig. B3, which shows the histogram of the slopes). At depths of $160-700 \mathrm{~m}$, more than $85 \%$ of the grid points have slopes larger than $S=10^{-4.5} \approx 3 \times 10^{-5}$ and hence are affected by the GKW scheme, but only $8 \%-9 \%$ of the points have slopes larger than $S=3 \times 10^{-3}$ and are thus affected by the DM scheme. Similarly, at $1000-3000-m$ depth, about $30 \%$ of the points are affected by the GKW scheme and only $12 \%$ are affected
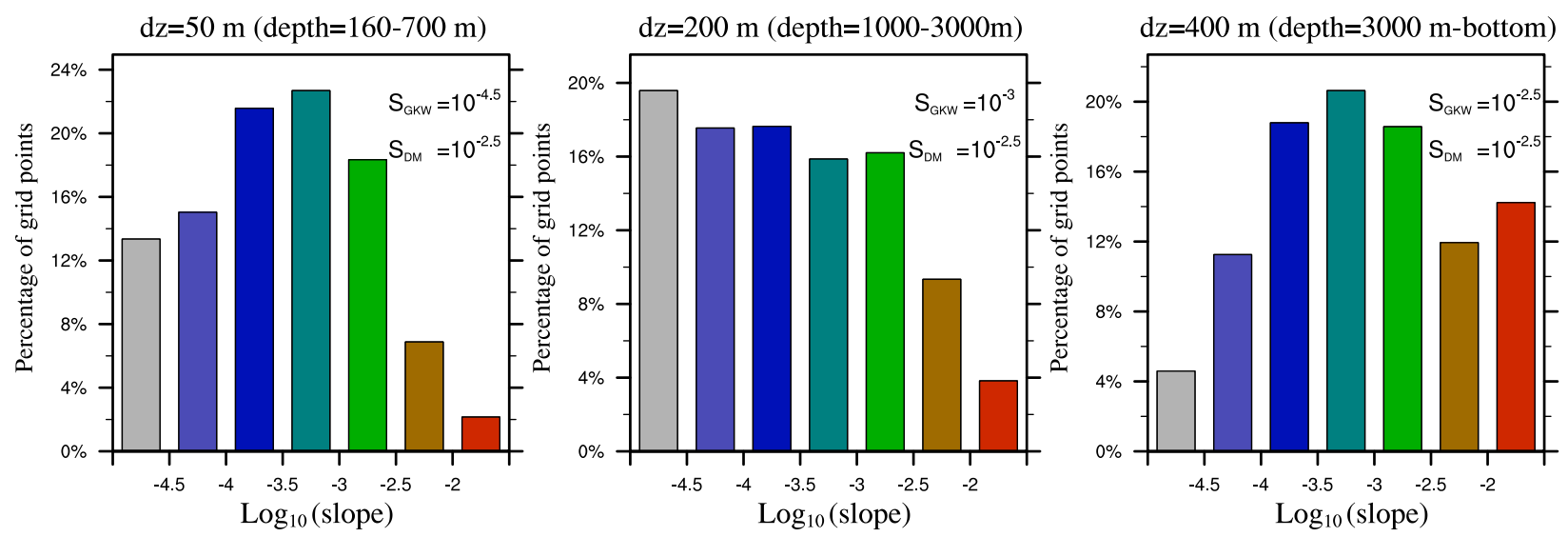

FIG. B3. Histograms of slopes of isopycnal surfaces (in logarithmic scale, from $20 \mathrm{yr}$ of control MPI-ESM data) in grid points with thicknesses $d z=$ (left) 50, (center) 200, and (right) $400 \mathrm{~m}$, representative of depth ranges 160-700 m, 1000-3000 m, and 3000 m-bottom, respectively. The top-right corner values denote the cutoff slopes $S_{\mathrm{GKW}}$ and $S_{\mathrm{DM}}$ of the GKW and DM schemes for the corresponding depths, above which the slope tapering is activated. 
by the DM scheme. The histogram thus explains why above $3000 \mathrm{~m}$ there is hardly any vertical heat convergence by isopycnal diffusion with the GKW scheme. Moreover, at depths larger than $3000 \mathrm{~m}$, about $30 \%$ of the points have slopes larger than the cutoff slopes of both schemes $\left(S \approx 3 \times 10^{-3}\right)$, explaining why at these depths both schemes produce very weak vertical heat convergences (Fig. B1).

The scaling factor of GKW scheme in Eq. (B1) is inversely proportional to $A_{I}$ through $\delta$. Higher values of $A_{I}$, therefore, cause smaller cutoff slopes, activating the GKW scheme in larger percentage of the grid points, reducing the overall impact of isopycnal diffusion. This is causing the emulated convergences to be even smaller than the actual online convergences when we use larger $A_{I}$ in Fig. B1. Such a relation does not hold in the DM scheme, implying that larger $A_{I}$ actually cause larger convergences, as also shown in Fig. B1.

\section{REFERENCES}

Banks, H. T., and J. M. Gregory, 2006: Mechanisms of ocean heat uptake in a coupled climate model and the implications for tracer based predictions of ocean heat uptake. Geophys. Res. Lett., 33, L07608, doi:10.1029/2005GL025352.

Bitz, C. M., P. R. Gent, R. A. Woodgate, M. M. Holland, and R. Lindsay, 2006: The influence of sea ice on ocean heat uptake in response to increasing $\mathrm{CO}_{2}$. J. Climate, 19, 2437-2450, doi:10.1175/JCLI3756.1.

Böning, C. W., A. Dispert, M. Visbeck, S. Rintoul, and F. U. Schwarzkopf, 2008: The response of the Antarctic Circumpolar Current to recent climate change. Nat. Geosci., 1, 864869, doi:10.1038/ngeo362.

Bouttes, N., J. M. Gregory, T. Kuhlbrodt, and T. Suzuki, 2012: The effect of windstress change on future sea level change in the Southern Ocean. Geophys. Res. Lett., 39, L23602, doi:10.1029/ 2012 GL054207.

- - — and J. A. Lowe, 2013: The reversibility of sea level rise. J. Climate, 26, 2502-2513, doi:10.1175/JCLI-D-12-00285.1.

Church, J. A., and Coauthors, 2011: Revisiting the earth's sea-level and energy budgets from 1961 to 2008. Geophys. Res. Lett., 38, L18601, doi:10.1029/2011GL048794.

—, D. Monselesan, J. M. Gregory, and B. Marzeion, 2013: Evaluating the ability of process based models to project sealevel change. Environ. Res. Lett., 8, 014051, doi:10.1088/ 1748-9326/8/1/014051.

Cox, M. D., 1974: Isopycnal diffusion in a z-coordinate model. Ocean Modell., 74, 1-5.

_- 1984: A primitive equation, 3 dimensional model of the ocean. GFDL Ocean Group Tech. Rep. 1, 147 pp.

Danabasoglu, G., and J. C. McWilliams, 1995: Sensitivity of the global ocean circulation to parameterizations of mesoscale tracer transports. J. Climate, 8, 2967-2987, doi:10.1175/ 1520-0442(1995)008<2967:SOTGOC $>2.0$. CO;2.

England, M. H., 1995: The age of water and ventilation timescales in a global ocean model. J. Phys. Oceanogr., 25, 2756-2777, doi:10.1175/1520-0485(1995)025<2756:TAOWAV>2.0.CO;2.

Exarchou, E., J.-S. Von Storch, and J. Jungclaus, 2013: Sensitivity of transient climate change to tidal mixing: Southern Ocean heat uptake in climate change experiments performed with ECHAM5/MPIOM. Climate Dyn., 42, 1755-1773, doi:10.1007/s00382-013-1776-y.

Frankcombe, L. M., P. Spence, A. M. Hogg, M. H. England, and S. M. Griffies, 2013: Sea level changes forced by Southern Ocean winds. Geophys. Res. Lett., 40, 5710-5715, doi:10.1002/2013GL058104.

Fyfe, J. C., and O. A. Saenko, 2006: Simulated changes in the extratropical Southern Hemisphere winds and currents. Geophys. Res. Lett., 33, L06701, doi:10.1029/2005GL025332.

Gent, P. R., and J. C. McWilliams, 1990: Isopycnal mixing in ocean circulation models. J. Phys. Oceanogr., 20, 150-155, doi:10.1175/1520-0485(1990)020<0150:IMIOCM>2.0.CO;2.

, J. Willebrand, T. J. McDougall, and J. C. McWilliams, 1995: Parameterizing eddy-induced tracer transports in ocean circulation models. J. Phys. Oceanogr., 25, 463-474, doi:10.1175/ 1520-0485(1995)025<0463:PEITTI >2.0.CO;2.

Geoffroy, O., D. Saint-Martin, D. J. L. Olivié, A. Voldoire, G. Bellon, and S. Tytéca, 2013: Transient climate response in a two-layer energy-balance model. Part I: Analytical solution and parameter calibration using CMIP5 AOGCM experiments. J. Climate, 26, 1841-1857, doi:10.1175/JCLI-D-12-00195.1.

Gerdes, R., C. Köberle, and J. Willebrand, 1991: The influence of numerical advection schemes on the results of ocean general circulation models. Climate Dyn., 5, 211-226, doi:10.1007/BF00210006.

Gordon, C., C. Cooper, C. A. Senior, H. Banks, J. M. Gregory, T. C. Johns, J. F. B. Mitchell, and R. A. Wood, 2000: The simulation of SST, sea ice extents and ocean heat transports in a version of the Hadley Centre coupled model without flux adjustments. Climate Dyn., 16, 147-168, doi:10.1007/s003820050010.

Gregory, J. M., 2000: Vertical heat transports in the ocean and their effect on time-dependent climate change. Climate Dyn., 16, 501-515, doi:10.1007/s003820000059.

- and Coauthors, 2005: A model intercomparison of changes in the Atlantic thermohaline circulation in response to increasing atmospheric $\mathrm{CO}_{2}$ concentration. Geophys. Res. Lett., 32, L12703, doi:10.1029/2005GL023209.

Griffies, S. M., A. Gnanadesikan, R. C. Pacanowski, V. D. Larichev, J. K. Dukowicz, and R. D. Smith, 1998: Isoneutral diffusion in a $z$-coordinate ocean model. J. Phys. Oceanogr., 28, 805-830, doi:10.1175/1520-0485(1998)028<0805: IDIAZC $>2.0 . \mathrm{CO} ; 2$.

Hallberg, R., and A. Gnanadesikan, 2006: The role of eddies in determining the structure and response of the wind-driven Southern Hemisphere overturning: Results from the Modeling Eddies in the Southern Ocean (MESO) project. J. Phys. Oceanogr., 36, 2232-2252, doi:10.1175/JPO2980.1.

Held, I. M., M. Winton, K. Takahashi, T. Delworth, F. Zeng, and G. K. Vallis, 2010: Probing the fast and slow components of global warming by returning abruptly to preindustrial forcing. J. Climate, 23, 2418-2427, doi:10.1175/2009JCLI3466.1.

Hieronymus, M., and J. Nycander, 2013: The budgets of heat and salinity in NEMO. Ocean Modell., 67, 28-38, doi:10.1016/ j.ocemod.2013.03.006.

Huang, B., P. H. Stone, A. Sokolov, and I. Kamemkovich, 2003: The deep-ocean heat uptake in transient climate change. J. Climate, 16, 1352-1362, doi:10.1175/1520-0442-16.9.1352.

Jackett, D. R., T. J. McDougall, M. H. England, and A. C. Hirst, 2000: Thermal expansion in ocean and coupled general circulation models. J. Climate, 13, 1384-1405, doi:10.1175/ 1520-0442(2000)013<1384:TEIOAC $>2.0$. CO; .

Kraus, E. B., and J. S. Turner, 1967: A one-dimensional model of the seasonal thermocline, II. Tellus, 19, 98-106, doi:10.1111/ j.2153-3490.1967.tb01462.x. 
Kuhlbrodt, T., and J. M. Gregory, 2012: Ocean heat uptake and its consequences for the magnitude of sea level rise and climate change. Geophys. Res. Lett., 39, L18608, doi:10.1029/ 2012GL052952.

Manabe, S., K. Bryan, and M. J. Spelman, 1990: Transient responses of a coupled ocean-atmosphere model to a doubling of atmospheric carbon dioxide. J. Phys. Oceanogr., 20, 722-749, doi:10.1175/1520-0485(1990)020<0722:TROAGO>2.0.CO;2.

Marsland, S. J., H. Haak, J. H. Jungclaus, M. Latif, and F. Röske, 2003: The Max Planck Institute global ocean/sea ice model with orthogonal curvilinear coordinates. Ocean Modell., 5, 91127, doi:10.1016/S1463-5003(02)00015-X.

McDougall, T. J., 2003: Potential enthalpy: A conservative oceanic variable for evaluating heat content and heat fluxes. J. Phys. Oceanogr., 33, 945-963, doi:10.1175/1520-0485(2003)033<0945: PEACOV $>2.0 . \mathrm{CO} ; 2$.

Morrison, K., O. A. Saenko, M. Hogg, and P. Spence, 2013: The role of vertical eddy flux in Southern Ocean heat uptake. Geophys. Res. Lett., 40, 5445-5450, doi:10.1002/2013GL057706.

Munk, W. H., 1966: Abyssal recipes. Deep-Sea Res. Oceanogr. Abstr., 13, 707-730, doi:10.1016/0011-7471(66)90602-4.

—_, and C. Wunsch, 1998: Abyssal recipes II: Energetics of tidal and wind mixing. Deep-Sea Res. I, 45, 1977-2010, doi:10.1016/ S0967-0637(98)00070-3.

Myhre, G., E. J. Highwood, K. P. Shine, and F. Stordal, 1998: New estimates of radiative forcing due to well mixed greenhouse gases. Geophys. Res. Lett., 25, 2715-2718, doi:10.1029/ 98GL01908.

Nikurashin, M., and G. Vallis, 2012: A theory of the interhemispheric meridional overturning circulation and associated stratification. J. Phys. Oceanogr., 42, 1652-1667, doi:10.1175/JPO-D-11-0189.1.

Pacanowski, R. C., and S. G. H. Philander, 1981: Parameterization of vertical mixing in numerical models of tropical oceans. J. Phys. Oceanogr., 11, 1443-1451, doi:10.1175/1520-0485(1981)011<1443: POVMIN $>2.0 . \mathrm{CO} ; 2$.

Rahmstorf, S., 1993: A fast and complete convection scheme for ocean models. Ocean Modell., 101, 9-11.

Raper, S. C. B., J. M. Gregory, and T. J. Osborn, 2001: Use of an upwelling-diffusion energy balance climate model to simulate and diagnose A/OGCM results. Climate Dyn., 17, 601-613, doi:10.1007/PL00007931.
Redi, M. H., 1982: Oceanic isopycnal mixing by coordinate rotation. J. Phys. Oceanogr., 12, 1154-1158, doi:10.1175/ 1520-0485(1982)012<1154:OIMBCR >2.0.CO;2.

Rugenstein, M. A. A., M. Winton, R. J. Stouffer, S. M. Griffies, and R. Hallberg, 2013: Northern high-latitude heat budget decomposition and transient warming. J. Climate, 26, 609-621, doi:10.1175/JCLI-D-11-00695.1.

Russell, J. L., 2006: The Southern Hemisphere westerlies in a warming world: Propping open the door to the deep ocean. J. Climate, 19, 6382-6390, doi:10.1175/JCLI3984.1.

Sen Gupta, A., A. Santoso, A. S. Taschetto, C. C. Ummenhofer, J. Trevena, and M. H. England, 2009: Projected changes to the Southern Hemisphere ocean and sea ice in the IPCC AR4 climate models. J. Climate, 22, 3047-3078, doi:10.1175/ 2008JCLI2827.1.

—, N. C. Jourdain, J. N. Brown, and D. Monselesan, 2013: Climate drift in the CMIP5 models. J. Climate, 26, 8597-8615, doi:10.1175/JCLI-D-12-00521.1.

Shaffrey, L. C., and Coauthors, 2009: UK HiGEM: The new UK high-resolution global environment model-model description and basic evaluation. J. Climate, 22, 1861-1896, doi:10.1175/ 2008JCLI2508.1.

Stevens, B., and Coauthors, 2013: Atmospheric component of the MPI-M Earth system model: ECHAM6. J. Adv. Model. Earth Syst., 5, 146-172, doi:10.1002/jame.20015.

Tailleux, R., 2010: Identifying and quantifying nonconservative energy production/destruction terms in hydrostatic Boussinesq primitive equation models. Ocean Modell., 34, 125-136, doi:10.1016/j.ocemod.2010.05.003.

Wigley, T. M. L., and S. C. B. Raper, 1992: Implications for climate and sea level of revised IPCC emissions scenarios. Nature, 357, 293-300, doi:10.1038/357293a0.

Wolfe, C. L., P. Cessi, J. L. McClean, and M. E. Maltrud, 2008: Vertical heat transport in eddying ocean models. Geophys. Res. Lett., 35, L23605, doi:10.1029/2008GL036138.

Wright, D. K., 1997: A new eddy mixing parametrization and ocean general circulation model. WOCE Newsletter, No. 26, WOCE International Project Office, Southampton, United Kingdom, 27-29.

Yin, J., 2012: Century to multi-century sea level rise projections from CMIP5 models. Geophys. Res. Lett., 39, L17709, doi:10.1029/2012GL052947. 